\title{
ADUBAÇÃO NITROGENADA EM NOVAS VARIEDADES DE CANA-DE-AÇÚCAR (CLONES SP)
}

\author{
BENEDITO FERNANDES FAGANELLO
}

Orientador: VALDOMIRO CORREA DE BITTENCOURT

Dissertação apresentada à Escola Superior de Agricultura "Luiz de Queiroz" da Universidade de São Paulo, para obtenção do título de Mestre em Solos e Nutrição de Plantas.

\author{
P I R A C I C A B A \\ Estado de São Paulo - Brasil \\ Novembro - 1981
}


A minha mãe, Thereza

com amor e carinho

ao meu pai, Guilherme

com amor e saudade

Dedico

A Teresinha, esposa

Fernanda, Fabiane

Flávia, Fabíola e

Florence, minhas filhas

Ofereço 


\section{AGRADEC IMENTOS}

Somos sinceramente gratos às seguintes pessoas e ins tituições:

Ao Prof.Dr. Valdomiro Correa de Bittencourt, pela orientação se gura, atenciosa e contínua prestada durante a execução do pre sente trabalho.

Ao Prof.Dr. Roberto Simionatto de Moraes, pelas sugestões e apôio nos estudos e realização das análises estatísticas.

Ao Prof.Dr. José Paulo Stupiello, pelas sugestões e apôio nos estudos e realização das análises químicas.

Aos técnicos agrícolas, Sr. José Roberto Braga, Benedito Nunes Correa e Bene Maurício Baglioni pela colaboração na instalação, condução e colheita dos ensaios.

A Coopersucar - Piracicaba, onde foram instalados e desenvolvidos os experimentos. 
I N D I C E

Página

LISTA DE TABELAS $\ldots \ldots \ldots \ldots \ldots \ldots \ldots \ldots \ldots \ldots \ldots \ldots$ iv

RESUMO $\ldots \ldots \ldots \ldots \ldots \ldots \ldots \ldots \ldots \ldots \ldots \ldots \ldots \ldots \ldots \ldots \ldots \ldots$ vi

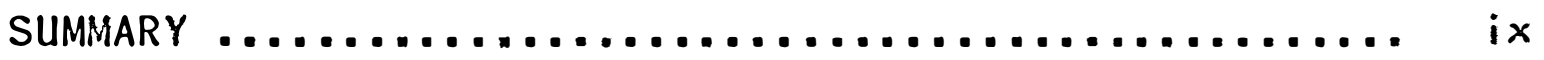

I. INTRODUÇÃo ............................. I

2. REVISÃo dE LITERATURA ..................... 3

3. MATERIAL E MÉTODOS ........................ 8

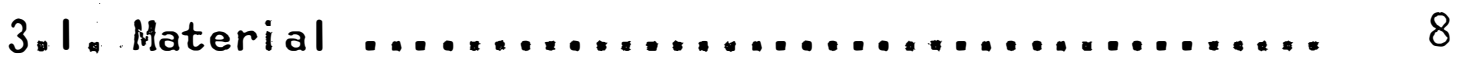

3.1.1. Solos ....................... 8

3.1 .2$, Adubos ........................ 8

3.1.3. Variedades de cana ................ 10

3.1.4. clima ........................... 10

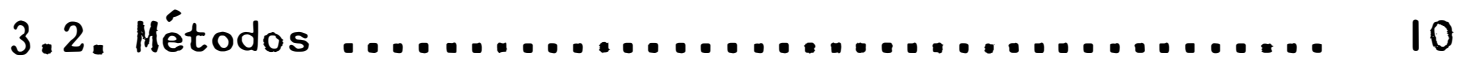

3.2.1. Atividades de campo .............. 10

3.2.1.1. Preparo de solos e mudas ...... II

3.2.1.2. Plantio e adubação .......... II

3.2.1.3. Colheita e obtenção de dados... 13

3.2.1.4. Análises tecnológicas ........ 13

4. RESUltados E dISCUSSÃo ................... 15

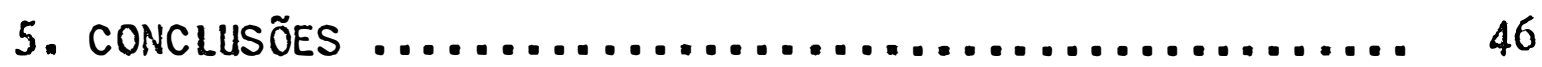

6. Literatura citada ....................... 47 


\section{LISTA DE TABELAS}

Página

1. Resultados da análise química dos solos .......... 9

2. Esquema da análise de variância ............... 12

3. Análise da variância dos dados de produção em tonela das de cana/ha no 10 corte e 10 ensaio ........... 16

4. Desdobramento estatístico de adubação $\times$ variedade de produção em toneladas de cana/ha no 10 corte e 10 en

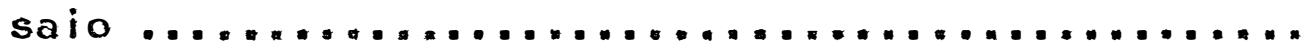

5. Dados de produção em toneladas de cana/ha para 10 corte e lo ensaio. Média 3 repetições ............

6. Análise da variancia dos dados de produção em tonela das de cana/ha no 2 o corte e lo ensaio ............ 20

7. Desdobramento estatístico de adubação $\times$ variedáde de produção em toneladas de cana/ha no 20 corte e 10 en saio

8. Dados de produção em toneladas de cana/ha para 2o corte e lo ensaio. Média 3 repetições ..............

9. Análise da variância dos dados de produção em tonela das de cana/ha no 1. corte e 2 ensaio.............

10. Desdobramento estatístico de adubação $\times$ variedade de produção em toneladas de cana/ha no lo corte e 20 en saio ........................................

11. Dados de produção em toneladas de cana/ha para lo corte e 20 ensaio. Média 3 repetições 
12. Análise da variância dos dados de produção em tonela das de cana/ha no 20 corte e 20 ensaio..

13. Desdobramento estatístico de adubação $\times$ variedade de produção em toneladas de cana/ha no 20 corte e 20 en saio.

14. Dados de produção em toneladas de cana/ha para 20 corte e 20 ensaio. Média 3 repetições............ 30

15. Análise de variância dos dados de pol em toneladas

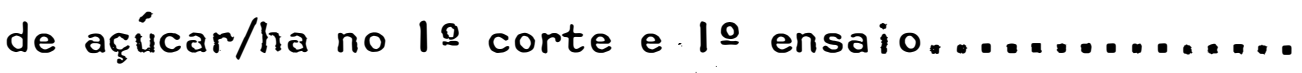

16. Desdobramento estatístico de adubação $\times$ variedade de pol em toneladas de açúcar/ha no lo corte e lo ensaio.

17. Dados de pol em toneladas de açúcar/ha para lo corte e 1 e ensaio. Média 3 repetiçôes.................

18. Análise de variância dos dados de pol em toneladas

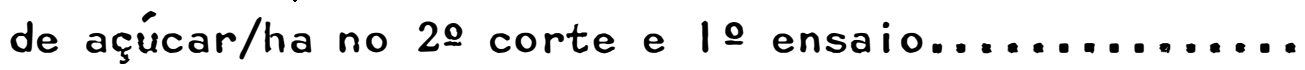

19. Desdobramento estatístico de adubação $\times$ variedade de pol em toneladas de açúcar/ha no 20 corte e Io ensa-

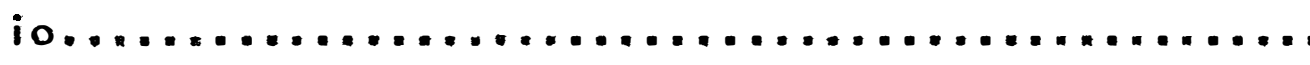

20. Dados de pol em toneladas de açúcar/ha para 2o corte e 19 ensaio. Média 3 repetições.

21. Análise da variância dos dados de pol em toneladas de açúcar/ha no 20 corte e 20 ensaio..............

22. Desdobramento estatístico de adubação $x$ variedade de pol em toneladas de açúcar/ha no 20 corte e 20 ensaio 
23. Dados de pol em toneladas de açúcar/ha para 20 corte e 20 ensaio. Média 3 repetições..................

'24. Análise da variância dos dados de pol em toneladas de açúcar/ha no 19 corte e 29 ensaio............4 43

25. Desdobramento estatístico de adubação $x$ variedade de pol em toneladas de açúcar/ha no 20 corte e 20 ensaio........................................ 44

26. Dados de pol em toneladas de açúcar/ha para 19 corte e 29 ensaio. Média 3 repetições................. 


\section{ADUBAÇÃO NITROGENADA EM NOVAS VARIEDADES \\ DE CANA-DE-AÇÚCAR (CLONES SP)}

Orientador: Prof.Dr. Valdomiro Correa de Bittencourt

Candidato: Benedito Fernandes Faganello

RESUMO

Um dos assuntos mais polêmicos e questionados por aqueles que se dedicam a pesquisa da cultura de cana-deaçúcar, é a resposta das diferentes variedades à adubação nitrogenada. Vários estudos realizados com cana-planta em condições de solos tropicais tem demonstrado que, por mais ilógi co que possa parecer, a cultura na maioria das vezes não responde às adubações nitrogenadas.

Objetivando conhecer e analisar o comportamen to de distintas variedades colocadas no mercado pela Coopersu car, frente a esse tipo de adubação, realizou-se o presente estudo onde utilizou-se o sulfato de amônio como fonte de ni trogênio em doses crescentes, o superfosfato simples e o cloreto de potássio como fontes de $\mathrm{P}_{2} \mathrm{O}_{5}$ e $\mathrm{K}_{2} \mathrm{O}$ respectivamente em doses fixas.

Em função dos resultados obtidos pode-se concluir que a maioria das variedades não reagiram a esta aduba- 
ção, ainda que diferenças no comportamento delas tivessem sido observadas. Outro aspecto positivo do trabalho é a indicação da variedade SP 70-3449 como detentora da maior produção. 


\title{
NITROGEN RESPONSE IN NEW SUGAR
}

CANE VARIETIES (CLONES SP)

Orientador: Prof.Dr. Valdomiro Correa de Bittencourt Candidato: Benedito Fernandes Faganello

SUMMARY

\begin{abstract}
Nitrogen fertilization of sugar cane is a very polemical subject, because of lack of response of this crop to some forms of nitrogen.
\end{abstract}

In order to know the behaviour of some sugar cane varieties sold by COOPERSUCAR, an experiment was carried out with Ammonium Sulfate, Superphosphate and Potassium cloride as sources of nitrogen, phosphorus and potassium.

The main conclusions were as follows:

1. results did not show any signficant effect of nitrogen for the most of varieties stu died.

2. the sugar cane variety identified as SP 703449 presented the highest production.

3. the NA 56-79, a sugar cane variety, show better Pol's results tham any other studied. 


\section{INTRODUÇÃO}

Atualmente o Brasil destaca-se como o primeiro produtor mundial de cana-de-açúcar, com área cultivada superior a 2 milhões de hectares, o que significa uma produção de 80 milhões de toneladas de cana.

Entretanto, mesmo tornando-se grande e poderoso em produção, o Brasil ainda apresenta em determinadas áreas, certos desniveis de produtividade. Analisando-se os fatores que contribuem para isso aparece em primeiro plano a adubação inadequada dos canaviais associado a variedades pouco produtivas, havendo então, a necessidade de criação de novos clones e do conhecimento de suas características quanto ao comportamento frente as fertilizações.

No presente trabalho procurou-se verificar, a reação das novas variedades de cana-de-açúcar da sigla SP sele cionadas pela Coopersucar a diferentes dosagens de nitrogênio, tendo-se em vista que, o custo desse nutriente é elevado, e 
portanto é de grande importância a obtenção de clones que apre sentem altas produtividades, mesmo na presença de baixas dosą gens desse nutriente. 
Após a queda de produção da lavoura cafeeira. a cultura da cana-de-açúcar sofreu uma expansão extraordinária, passando a ocupar lugar de destaque na agricultura brasileira. Ultimamente, verifica-se a repetição deste processo com os incrementos fornecidos pela atual política energética alternativa, representada pelos programas pró-álcool.

Em consequência, a grande preocupação daqueles que trabalham neste campo, tem sido o aumento constante da relação produção/área, sem prejuízo da qualidade da matéria prima. Nesta busca técnica, numerosos pesquisadores tem desenvol vido estudos principalmente em relação a influência da adubação, fator limitante para se atingir aquele objetivo.

Neste contexto a fertilização nitrogenada tem, cada vez mais, apresentado problemas e levantado dúvidas, a ponto de haver uma intensificação de projetos para se determinar sua real atuação. O maior testemunho disto é o aparecimen 
to de variedades que tem sido classificados conforme sua res. posta a este nutriente.

$$
\text { Assim, já em 1955. HALAIS desenvolveu um expe }
$$
rimento no qual estudou diversas variedades de cana de açúcar e encontrou diferentes reações varietais a adubação nitrogena da. Nessa mesma época HUMBERT (1955) no Hawai concluiu que algumas variedades de cana de açúcar são capazes de utilizar níveis mais elevados de nitrogênio que outras. Esse mesmo au tor logo após cita um trabalho realizado no México que mostrou respostas lineares ao aumento de niveis de nitrogênio, na va riedade NCO 310. Esse efeito foi atribuido ao nitrogênio aumentar a brotação e reduzir a mortalidade dos perfilhos duran te o desenvolvimento da cana de açúcar (WU e LOH, 1963).

Além do efeito do nutriente em si sobre a cu! tura, é importante a época de sua aplicação e, conforme concluiram ORTEGA e SEGURA (1963), os melhores rendimentos em açúcar podem ser obtidos quando o nitrogênio é aplicado na cana com 4 meses de idade.

Um outro aspecto que também tem sido ventilado é com respeito a forma e dose do fertilizante a ser empregado. Desse modo, ASO e FOGLIATA (1963) usando o sulfato de amônio em doses crescentes concluiram que com $150 \mathrm{~kg}$ de nitro gênio por hectare obtém-se o máximo rendimento em tonelagem de cana de açúcar. E com $100 \mathrm{~kg}$ de nitrogênio por hectare ob tém-se a maior produção de açúcar por hectare.

Quanto a forma do adubo nitrogenado vários tra balhos levados a efeito tem mostrado que a uréia é a fonte 
mais econômica, fornecendo a maior produção de açúcar por hectare (TOIT, 1967; MUSA, 1968; YOON e KOK, 1968; YOON, 1971 ; SEGURA e MARTINEZ, 1973).

Conforme se verifica, os dados até aqui apresentados referem-se a pesquisas conduzidas em diversas partes do mundo, os quais servem para nos dar uma idéia geral a respeito do comportamento da cultura, frente a fertilizações nitrogenadas. Entretanto deve ser considerado que o efeito dos fertilizantes deve ser verificado para cada região em particular, devido as suas próprias características de solo e clima.

Em nossas condições, ALVAREZ et alii. (1960) em solo classificado como Terra Roxa Misturada e usando a varieda de co 419, observaram que existem influências positivas do nitrogênio e do fósforo na produção e qualidade do caldo de cana de açúcar.

Como já foi apontado anteriormente, a fonte de nitrogênio é sumamente importante para uma real avaliação da sua absorção pela planta. Assim. ARRUDA (1960) verificou em experimento instalado em Terra Roxa da Estação Experimental de Ribeirão Preto, que o uso de adubos nitrogenados, $120 \mathrm{~kg}$ de $\mathrm{n}$ trogênio/ha, aumentaram a produção da cana de açúcar em 19\% em relação a testemunha com apenas fósforo e potássio, porém nã̃o encontrou diferença significativa entre as produções proporcio nadas pelas diferentes formas destes adubos: sulfato de amonia, nitrocálcio e uréia.

$$
\text { Conforme já é amplamente conhecido os fertili- }
$$
zantes nitrogenados apresentam uma alta solubilidade e a indi- 
cação de se proceder o parcelamento na adubação é, hoje, práti ca usual. A confirmação deste fato surgiu com TOLEDO e NOVAIS em 1962 ao estudarem a influência da adubação nitrogenada em cobertura, na produção de cana de açúcar. Concluiram que ela influi acentuadamente e que o tratamento mais interessante do ponto de vista prático e econômico é aquele em que se coloca a metade de nitrogênio mais fósforo e potássio no plantio, e metade de nitrogênio em cobertura no mês de outubro. 0 estudo es tatístico dos dados, entretanto, revelou que não foram signifi cativas as diferenças entre as médias de produção.

Trabalho semelhante foi desenvolvido por ALVAREZ et alii (1963) que observaram que uma única aplicação de nitrogênio determinou uma produção média de 181 ton/ha. Com - fracionamento a produção, passou para 191 ton/ha.

Por sua vez ESPIRONELLO et alii. (1977) desen volvendo um trabalho com vários solos (4 latossolos e 1 podzolizado de Lins e Marília var. Marília) concluiram que tanto a produção de cana em toneladas como a produção de açúcar, aumen taram significativamente com o nitrogênio aplicado totalmente aos 2 meses. A aplicação parcelada aumentou a produção de cana em dois experimentos em Latossol Vermelho Escuro (LE) e no Latossol Roxo (LR).

Entretanto de uma maneira geral, a resposta a adubação nitrogenada tem sido polêmica, pois, em vários trabalhos não se confirmou o seu efeito quando se levou em consideração o aspecto varietal. Como exemplo, cita-se ORLANDO et alii. (1977) que estudaram esse tipo de fertilização nas variedades CB 41-76, CO 740, IAC 51/205 e NA 56-62 instaladas em so 
Io Latossol Vermelho Escuro var. orto. O ensaio foi colhido aos 18 meses de idade sendo obtidas as produçóes em toneladas de cana por hectare, as porcentagens de pol na cana e os açúca res redutores. Concluiram não haver influência do $N$ (doses e épocas de aplicação) nas produtividades agrícolas e não se observou efeito dos tratamentos nitrogenados sobre a qualidade industrial do caldo.

Resultados opostos são aqueles apontados por AZEREDO et ali i. (1980) objetivando quantificar a resposta das variedades de cana $C B$ 45-39, CB 47-89, CB 51-22 e CB 56-20, às diferentes doses de nitrogênio e também a dose econômica daque le nutriente. Observaram que houve efeito dos tratamentos para as produções de cana, pol/ha e para a porcentagem de fibra. A dose económica de nitrogênio calculada em função da relação de preços da tonelagem de cana na esteira e kg de nitrogênio (18:1) foi de 156,97 kg de nitrogênio por ha.

Num trabalho realizado por RUSCHELL et alii. (1977) usando $N^{15}$ como sulfato de amônio na var. CB 41-76, ficou concluido que dos $100-200 \mathrm{~kg}$ de $\mathrm{N} / \mathrm{h} a$ colocados apenas 21,0 e $24,8 \%$ são utilizados respectivamente pela cultura.

Finalmente na escasses de dados exixtentes, ainda referências são feitas a épocas adequadas para análises foliares (MALAVOLTA et alii, 1963; TEIXEIRA, 1978; CRLANDO e ZAMBELLO, 1979) assim como a influência de irrigação sobre a adubação NPK em cana de açúcar (ORLANDO et alii, 1980). 
3. MATERIAL E MÉTODOS

\author{
3.1. Material
}

3.1.1. Solos

Os ensaios foram instalados na Estação Experi mental da Coopersucar em Piracicaba em dois tipos de solos classificados, segundo DEMATTÊ (1971), como Latossol Roxo e Podzólico Vermelho Amarelo variação Laras. A avaliação das con dições de fertilidade dos locais, foi feita através de análises químicas de rotina (Boletim do Instituto Agronômico) dos dois tipos de solos e a profundidade de 0-20 e $20-40 \mathrm{~cm}$, e são apresentados no Quadro 1.

\title{
3.1.2. Adubos
}

Nos ensaios utilizou-se o sulfato de amônio 


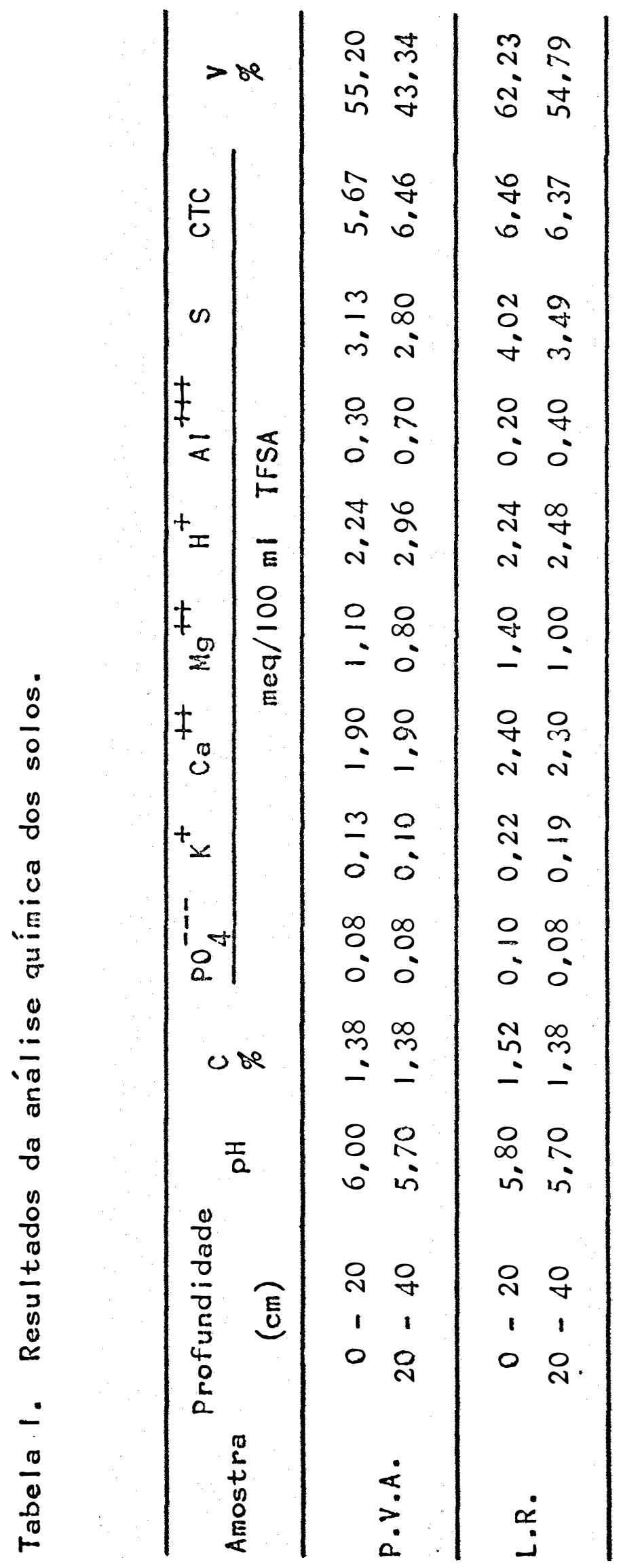


$(20 \% \mathrm{~N})$, o super fosfato triplo $\left(45 \% \mathrm{P}_{2} \mathrm{O}_{5}\right)$ e o cloreto de po tássio $\left(00 \% K_{2}\right)$ em dosagem fixa para o $P$ e $K$, variando-se o $N$.

3.1.3. Variedades de cana

Objetivando-se a obtenção de dados básicos sobre adubação das variedades $S P$, empregou-se no estudo os culti vares nomeados de SP 70-3145, SP 70-3303, SP 70-3153, SP 703304, SP 70-3370, SP 70-3420, SP 70-3449 e SP 70-3471. Para efeito de comparação, ou testemunha, utilizou-se a CB $41-76$ e NA $56-79$.

$$
\text { 3.1.4. Clima }
$$

O clima do município é do tipo mesotérmico CWA, isto é, subtropical úmido com estiagem no inverno. As chuvas do mes mais seco não atinge $30 \mathrm{~mm}$ e a temperatura do mês mais quente é superior a $22^{\circ} \mathrm{C}$ e a do mês mais frio é inferior a 18 ${ }^{\circ} \mathrm{c}$.

3.2. Métodos

3.2.1. Atividades de campo 
3.2.1.1. Preparo de solo e mudas

No mês de janeiro, devido as condições de umidă de apropriada do solo, iniciou-se o preparo do terreno efetuan do-se uma aração seguida de uma gradeação para destorroamento. Em sequência, procedeu-se ao tratamento das mudas selecionadas e coletadas em viveiro próprio, com 12 meses de idade em tanque com Benlate a $45 \mathrm{gr} / 100$ litros de $\mathrm{H}_{2} \mathrm{O}$ por 10 minutos.

3.2.1.2. Plantio e adubação

Dada a existência de sementeiras em brotação, houve a necessidade de nova gradeação leve no terreno, após o que procedeu-se a sulcação com $30 \mathrm{~cm}$ de profundidade. Cada parcela representou um número de 5 sulcos, com 8 m de compri mento, espaçados de $1,40 \mathrm{~m}$, perfazendo uma área totai de 56 $\mathrm{m}^{2}$ tendo aqui após a eliminação da bordadura (laterais), restou uma área útil de $33.6 \mathrm{~m}^{2}$.

Em cada parcela foram distribuidos 200 toletes de 2 gemas sendo que em cada linha de 8 metros foram plantados 40 toletes, resultando numa densidade de $10 \mathrm{gemas} / \mathrm{m}$.

Os sulcos foram polvilhados antes do plantio com Aldrin 5\%.

Em seguida, efetuou-se a adubação no sulco nos seguintes niveis de dosagens: 


$\begin{array}{llll}N & -0 & 60 & 120 \\ P_{2} O_{5}-120 & 120 & 120 \\ K_{2} O^{-140} & 140 & 140 \text {, parcelando-se }\end{array}$

- último nível de $N$ em $60 \mathrm{~kg}$ no plantio e 60 no 80 mês de idade.

O delineamento usado foi o "Split Plot" em blocos casualizados e o esquema da análise de variância, em blocos com parcelas subdivididas (Tabela 2).

Tabela 2. Esquema da análise de variância.

\begin{tabular}{lc}
\hline C. Variação & G.L. \\
\hline Blocos & 2 \\
Variedades $(V)$ & 9 \\
Resíduo (a) & 18 \\
\hline (Parcelas) & $(29)$ \\
\hline Adubação (A) & 2 \\
Interação A $\times$ V & 18 \\
Resíduo (b) & 40 \\
\hline Total (Sub-parcelas) & 89 \\
\hline
\end{tabular}


0 ensaio 1 foi instalado em 25 de março de 1977 e o 10 corte efetuado em 12 de agosto de 1978. O segundo corte ocorreu em 14 de setembro de 1979.

0 ensaio 2 teve seu plantio realizado a 05 de abril de 1977, seu primeiro corte a 26 de outubro de 1978 e o 2o corte em 06 de novembro de 1979.

3.2.1.3. Colheita e obtenção de dados.

Ocorrendo a germinação, 60 dias após o plantio, procedeu-se sua contagem e depois de 75 dias a contagem dos brotos em duas linhas, e a medição da altura dos colmos em 3 linhas.

No desenvolvimento normal da cultura, houve a necessidade de duas capinas, e com 18 meses, procedeu-se a coTheita dos ensaios e respectivas pesagens. Paralelamente efetuou-se a contagem do número de colmos totais e mediu-se o diâ metro e comprimento de $20 \mathrm{colmos} / \mathrm{parcel}$ a.

\subsubsection{Análises tecnológicas}

Do material colhido de cada parcela, enviou- se amostras de 18 colmos para o laboratório, as quais foram anali sadas pelo método da prensa hidráulica conforme metodologia descrita pela COOPERSUCAR (1980). No caldo extraído pela pren 
sa determinou-se a pol segundo LANE e EYNON (1923), sendo efe tuados cálculos da pol/ha conforme parâmetros fornecidos por STURION E FERNANDES (1979), 
Na tabela 3 , onde se apresenta a análise de vạ riância dos resultados obtidos no 10 corte do 10 ensaio, mostra a significância do teste $F$ aplicado para as variedades utilizadas e adubação efetuada. Sua interpretação demonstra a resposta positiva à adubação nitrogenada, ainda que na análise da interação adubação $x$ variedades, tal significância não se apresente, apesar de se observar haver variações em função das diferentes doses aplicadas.

Para se conhecer melhor o comportamento especí fico das variedades diante desta adubação, efetuou-se o desdo bramento do modelo estatístico aplicado, que se constitue nos dados apresentados na tabela 4 . Sua análise confirma o F não significativo demonstrando, maıs uma vez, a não existência de uma variedade que responda, de maneira particular, à adubação nitrogenada.

Esta constatação requereu um estudo dirigido ao comportamento varietal individual em função das tres doses 


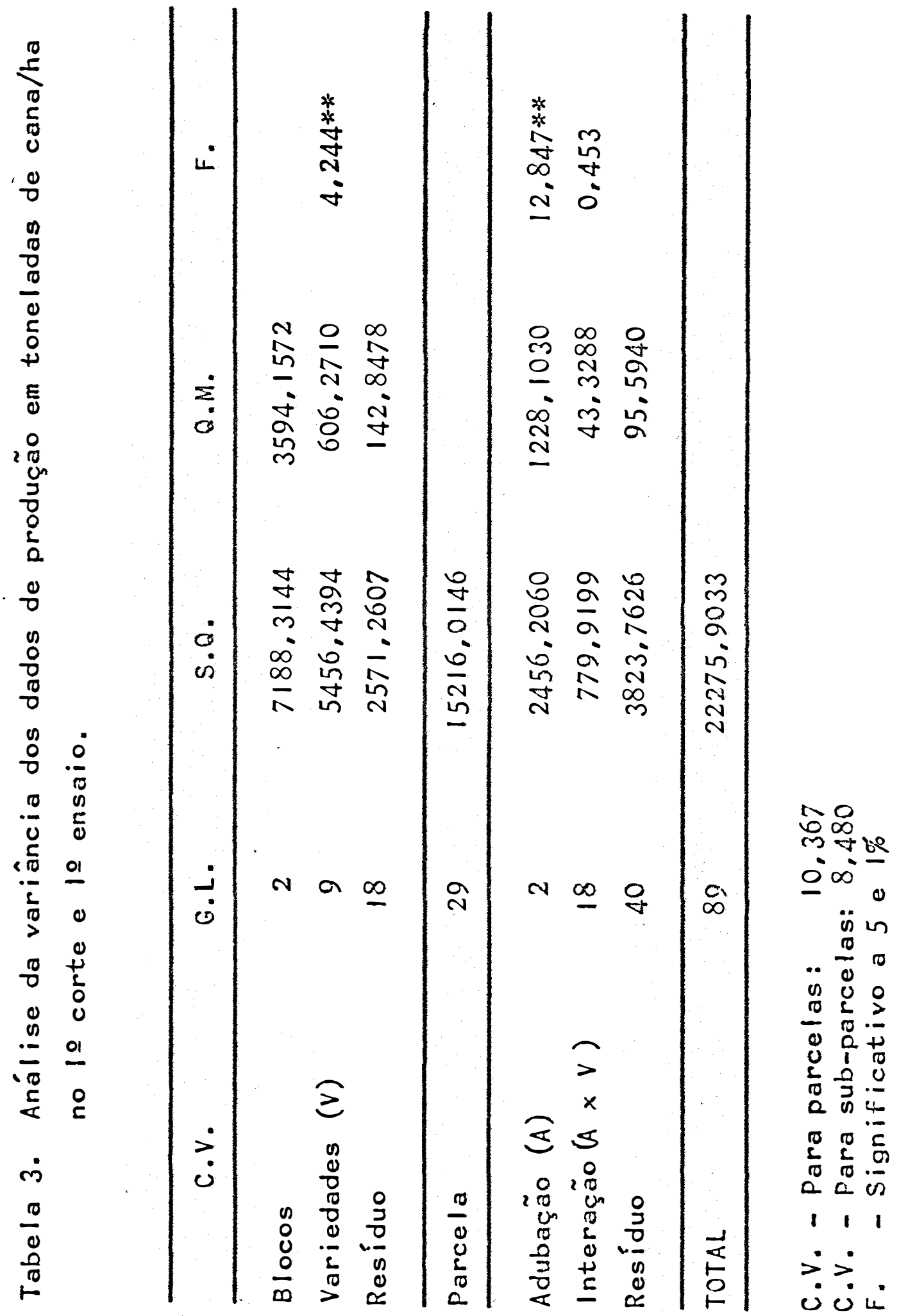




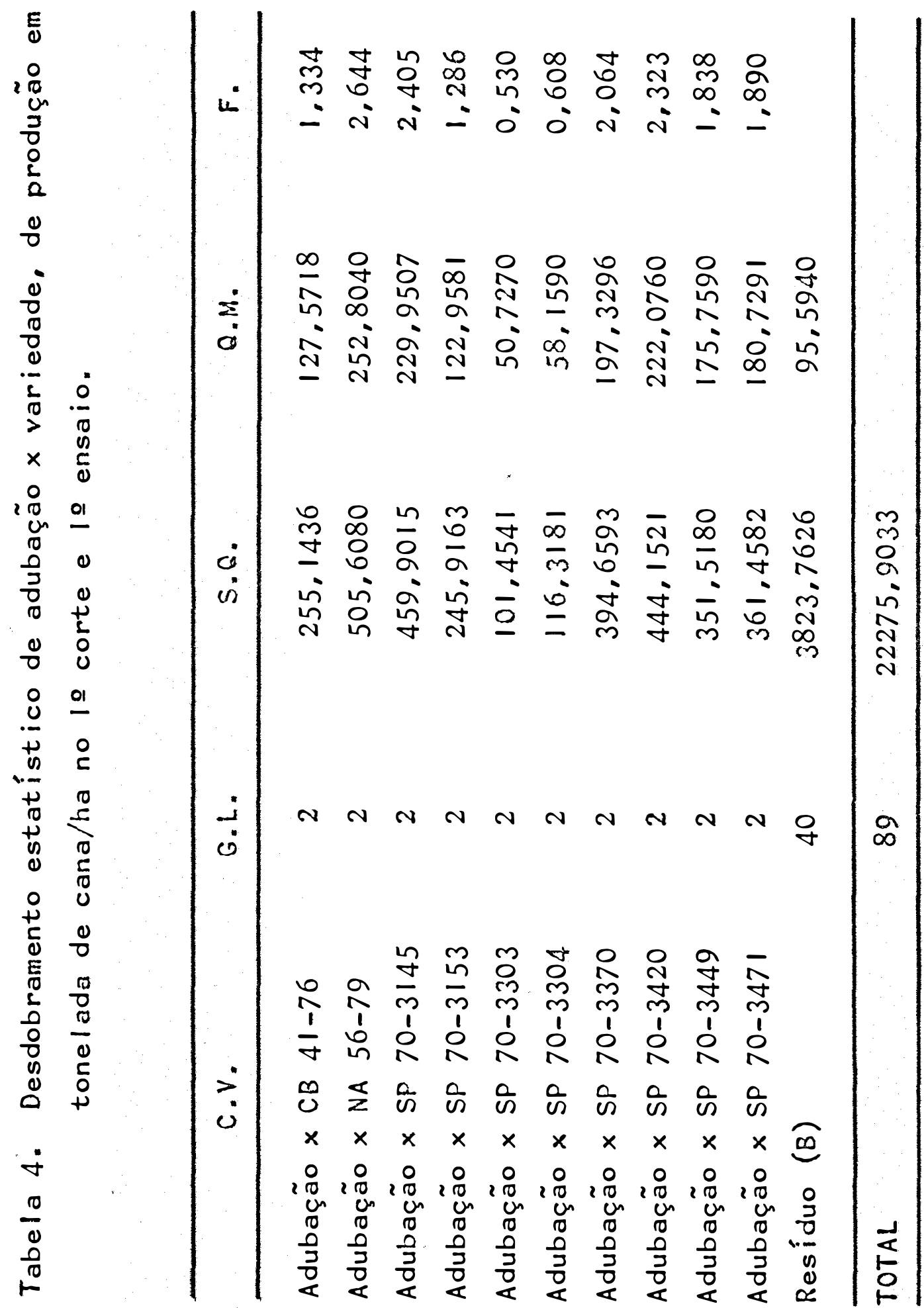


de $N$ aplicados, o que se apresenta na tabela 5. Observa - se então, que a maior produção é a apresentada pela variedade SP 70-3449 com 131,3211 ton/ha em média, demonstrando sua melhor performance mesmo quando comparada com a NA 56-79, considera'da a melhor tanto sob o aspecto de produção de cana/ha quanto sob o aspecto de produção de açúcar.

Outro ponto bastante significativo a ser considerado é o fato de que a SP 70-3449 apesar de haver respondido favoravelmente aos níveis de 60 e $120 \mathrm{~kg} \mathrm{~N} / \mathrm{ha}$ apresentou alta produtividade, mesmo com a dose 0 do nutriente, enquan to que as outras variedades tenderam a mostrar menores valo res. Uma possível explicação para isso se deve a interação da variedade com a rizosfera nos processos de fixação assimbiótí ca do nitrogênio.

Outra contribuição importante que pode ser ex traída da análise destes dados da tabela 5 é a indicação de ser a dose $60 \mathrm{~kg} / \mathrm{ha}$ de $N$ a mais indicada, pois, de maneira ge ral, as respostas demonstram haver pouca diferença entre as produções obtidas neste nível e aquelas conseguidas com aplicação de $120 \mathrm{~kg} / \mathrm{ha}$.

Analisando-se, agora, os resultados obtidos pạ ra 029 corte apresenta-se a tabela 6 onde, através da análise de variância dos dados obtidos, nota-se que o teste $F$ mostra-se significativo ao nível de 5 e $1 \%$ para variedade e a $1 \%$ para adubação, havendo a repetição da situação anterior em não se obter diferenças significativas para a interação doses $x$ variedades. 


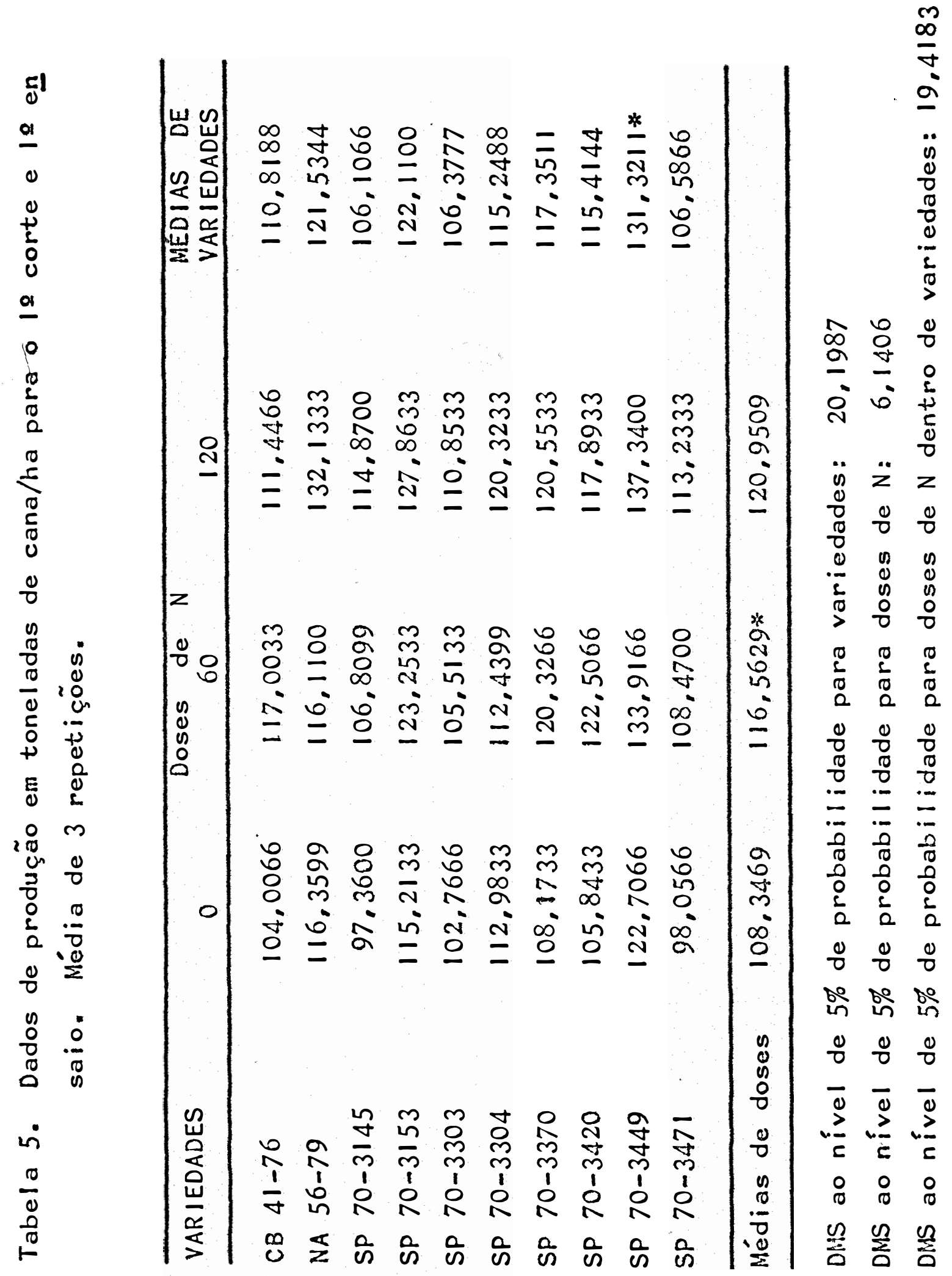




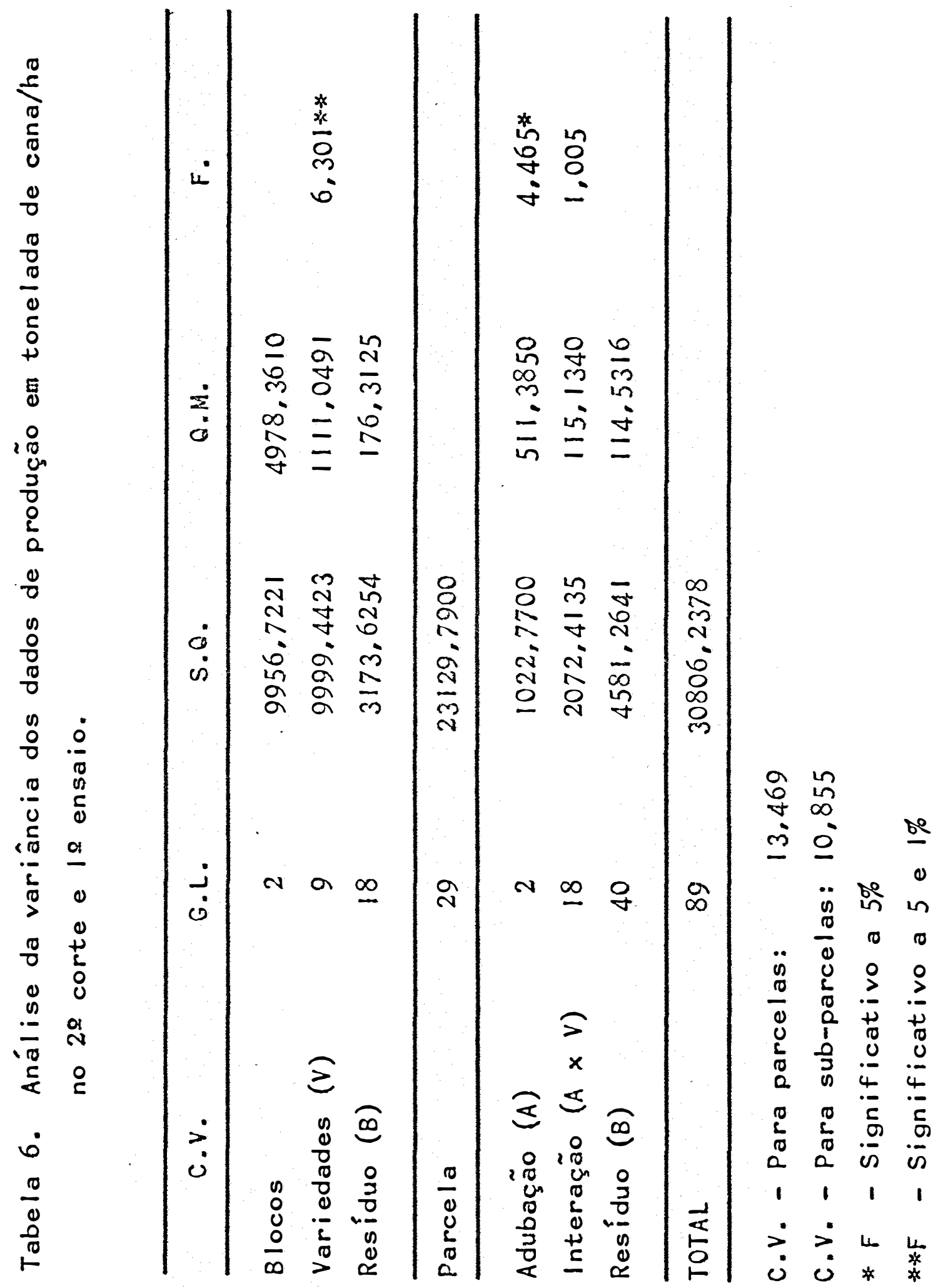


A tabela 7 mostra que para o tratamento esta tístico, as interações de doses $\times$ SP 70-3145 e doses $\times$ SP 703370, foram significativas para os níveis já considerados.

Buscando uma resposta mais direta em termos deste comportamento, elaborou-se a tabela 8 que demonstra haver resposta na dose de $60 \mathrm{~kg} / \mathrm{ha}$ a variedade $S P$ 70-3370 e na de $120 \mathrm{~kg} / \mathrm{ha}$ para a SP $70-3145$.

Considerando-se as médias apresentadas pelas variedades em função da adubação, nota-se que é maior para a dose $120 \mathrm{~kg} / \mathrm{ha}$, apesar de não haver diferenças significativas entre esse valor e o obtido para a dose de $60 \mathrm{~kg}$. N/ha.

Ressalva tem que ser feita, uma vez mais, ao comportamento de SP 70-3449 que teve melhor desempenho eni pro dução comparada a NA 56-79, independentemente da adubação. Outro aspecto de importância capital é a observância, nesta tabe la, que esta variedade em nível $O$ (zero) de $N$ produziu mais que qualquer outra demonstrando não depender da adubação para apresentar a produtividade mais alta, embora não havendo diferenças significativas estatisticamente.

Ainda buscando mais informações sobre os aspec tos considerados efetuou-se o ensaio 2 e os resultados dos dois cortes foram tratados estatisticamente. A tabela 9 constituída da análise de variância, apresenta não significância do tes te $F$ para resposta a adubação nitrogenada.

A tabela 10 apresenta $F$ significativo para a interação de CB 41-76 com a adubação. Deve-se considerar ao 


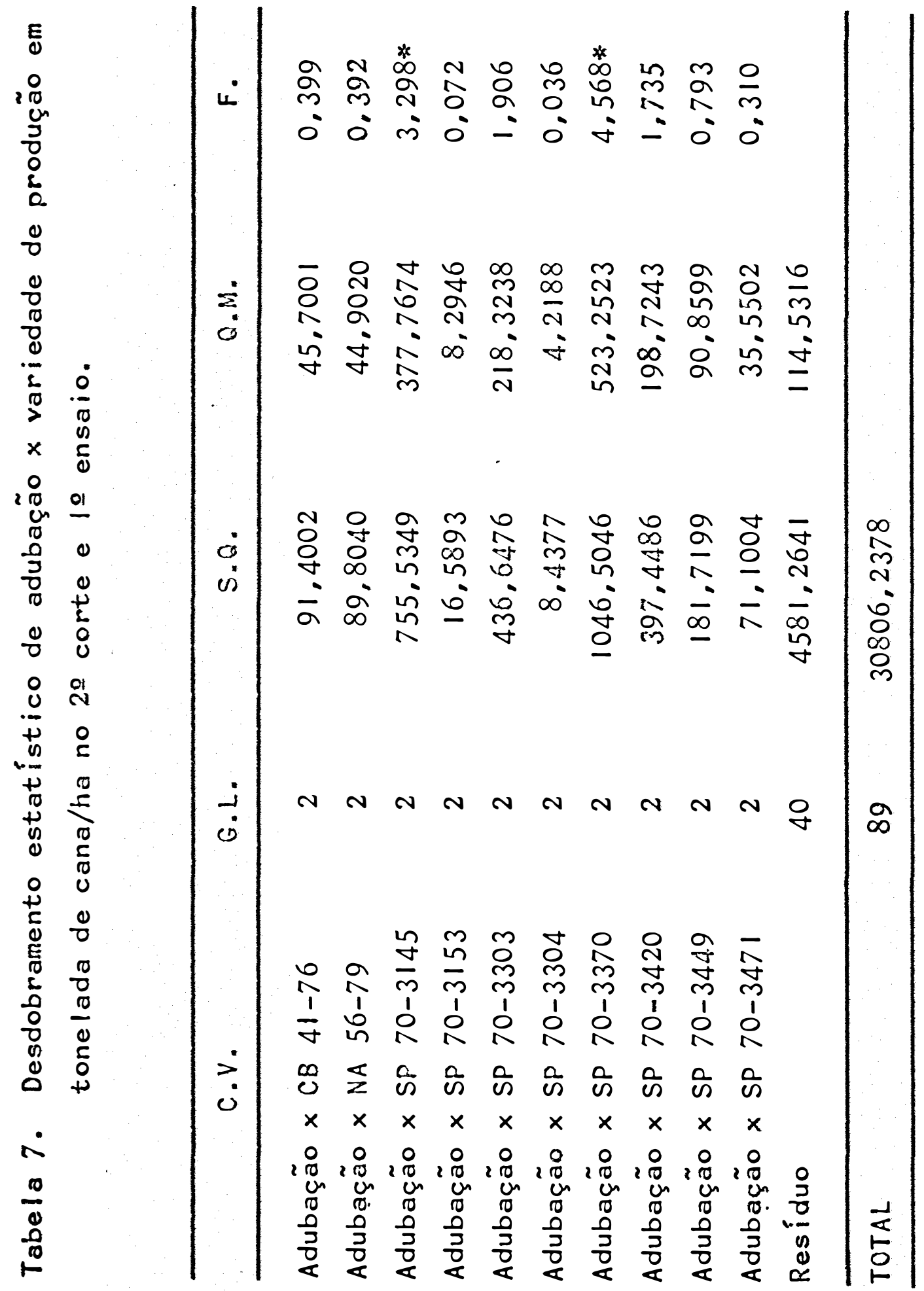




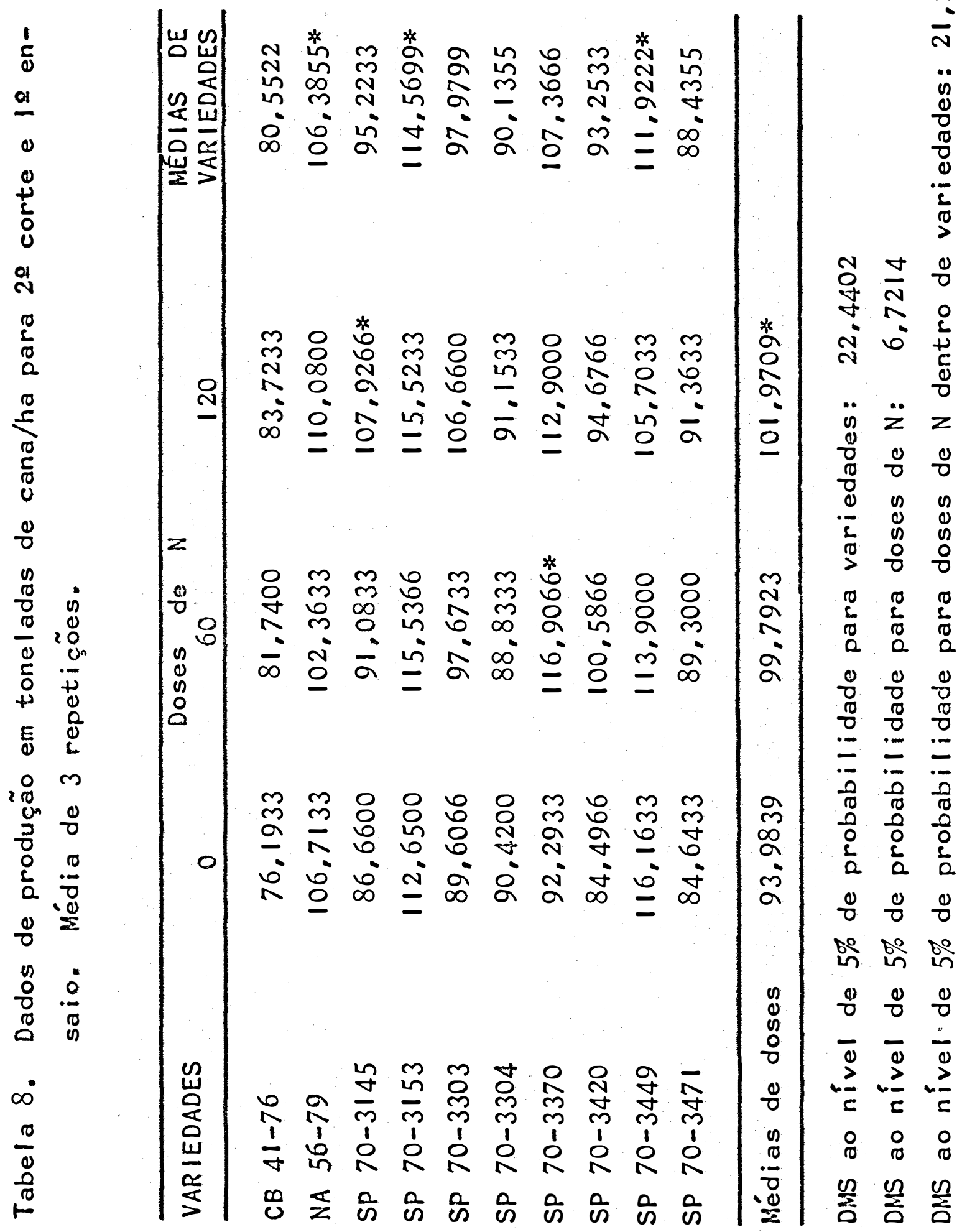




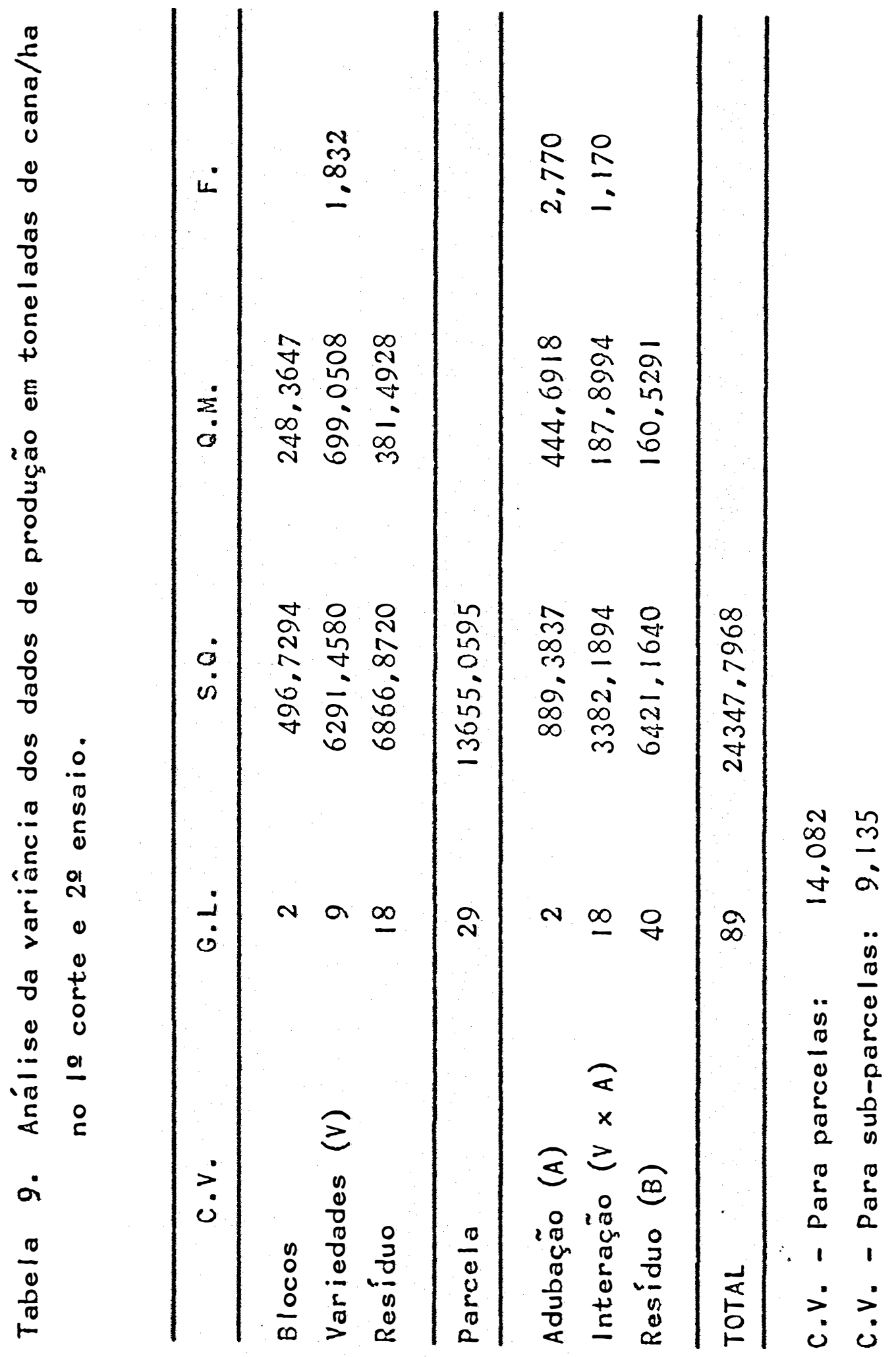




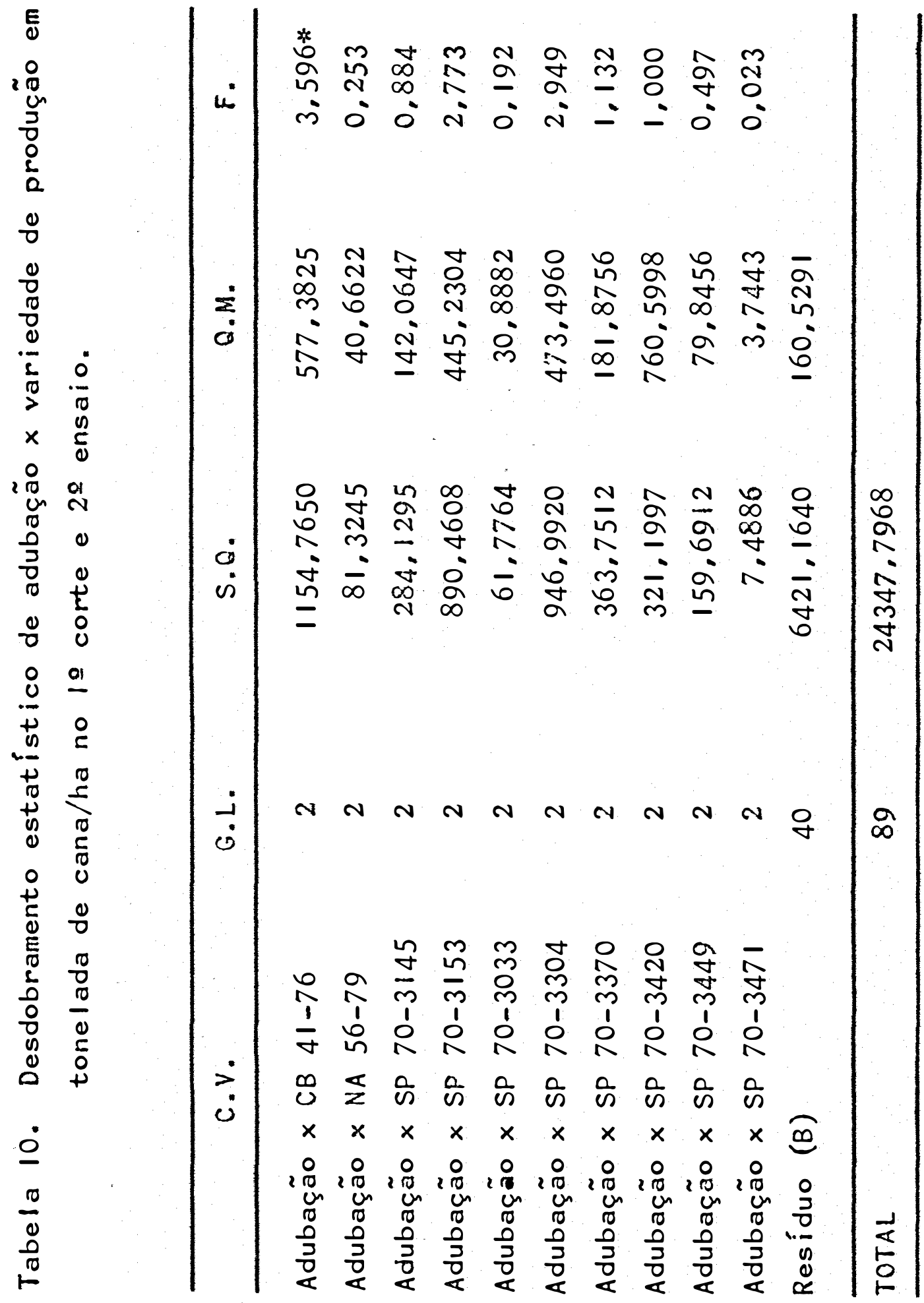


analisar-se este dado, que esta variedade foi de baixa produti vidade e, como o esperado, reagiu bem a uma adubação nitrogena da ao nível de $120 \mathrm{~kg} / \mathrm{ha}$. Esta resposta pode ser melhor avaliada examinando-se a tabela $\mid l$ que também apresenta uma produ ção razoável para a CB e indica a SP 70-3153 e a NA 56-79 como as que apresentam as melhores médias de produção.

020 corte aponta resultados e comportamentos pouco semelhantes aos anteriores. A tabela 12 mostra os da dos que se referem a esse tratamento e nela pode-se observar a significancia a $5 \%$ para as variedades.

No consequente desdobramento destes dados houve, novamente, a não significância da interação adubo $x$ variedade demonstrando que não houve resposta a adubação (tabela 13).

A tabela 14 mostra os resultados obtidos do comportamento varietal deste 20 ensaio. Através da sua análi se pode-se notar que a SP 70-3449 volta a apresentar a média de produção mais alta entre todas as variedades e nos 3 níveis de nitrogênio, produções semelhantes.

A produção de açúcar é o próximo dado a ser analisado.

A tabela 15 apresenta os dados da análise de variância, com $F$ significativo para produção $x$ adubação mostrando o incremento das produções de açúcar frente a adubação nitrogenada.

A fim de se obter uma resposta mais especifica desta produção/variedade, efetuou-se o desdobramento do modelo 


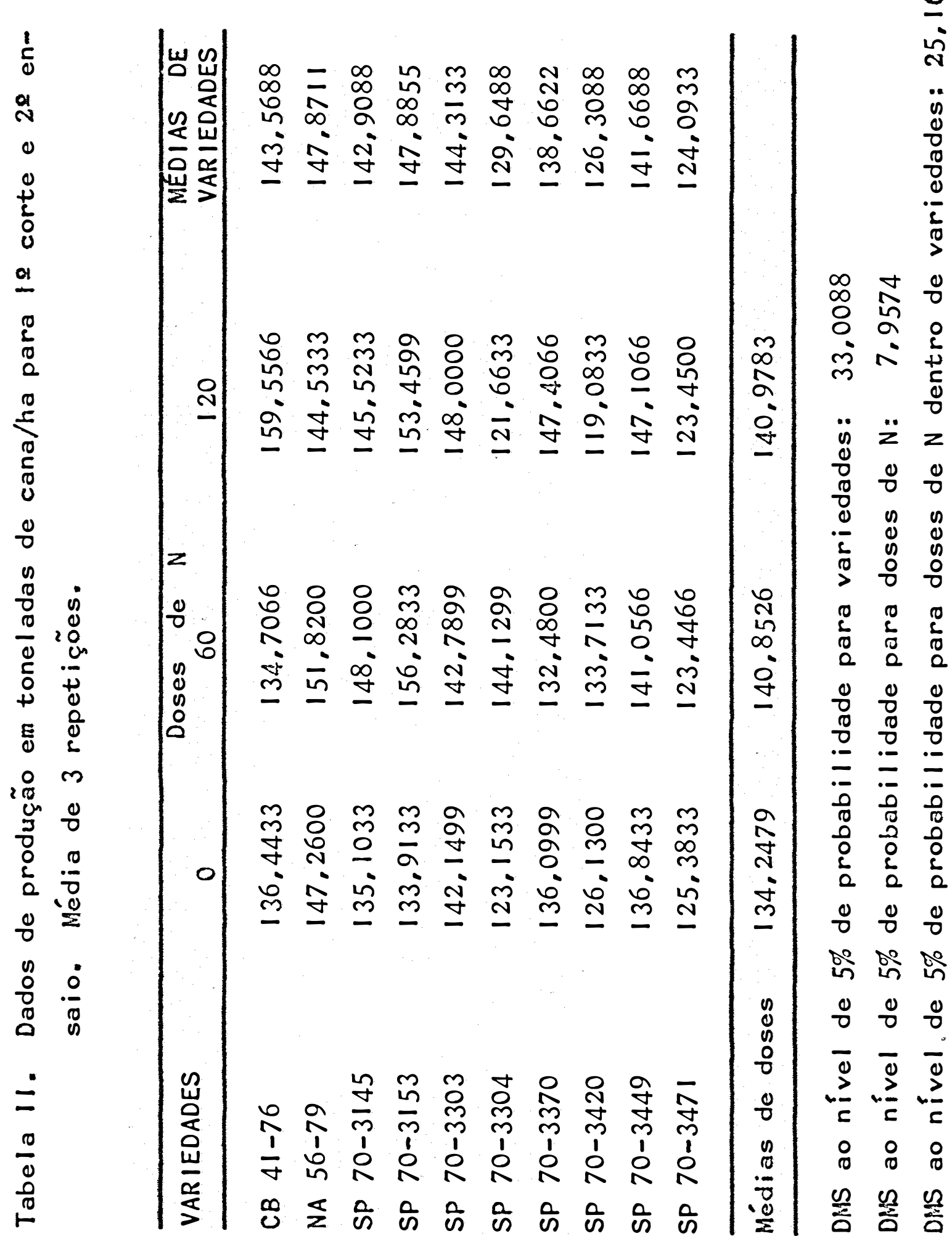




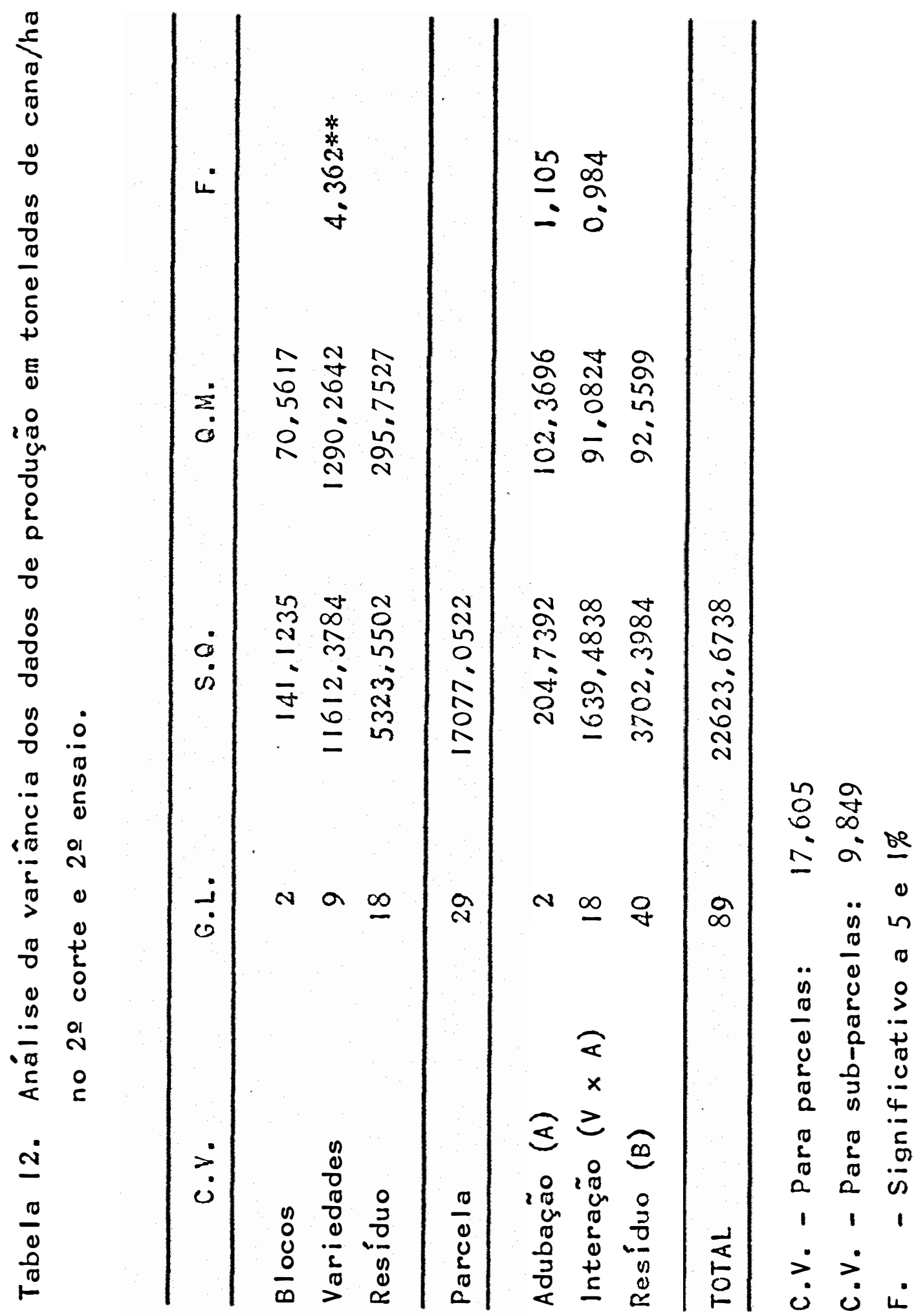




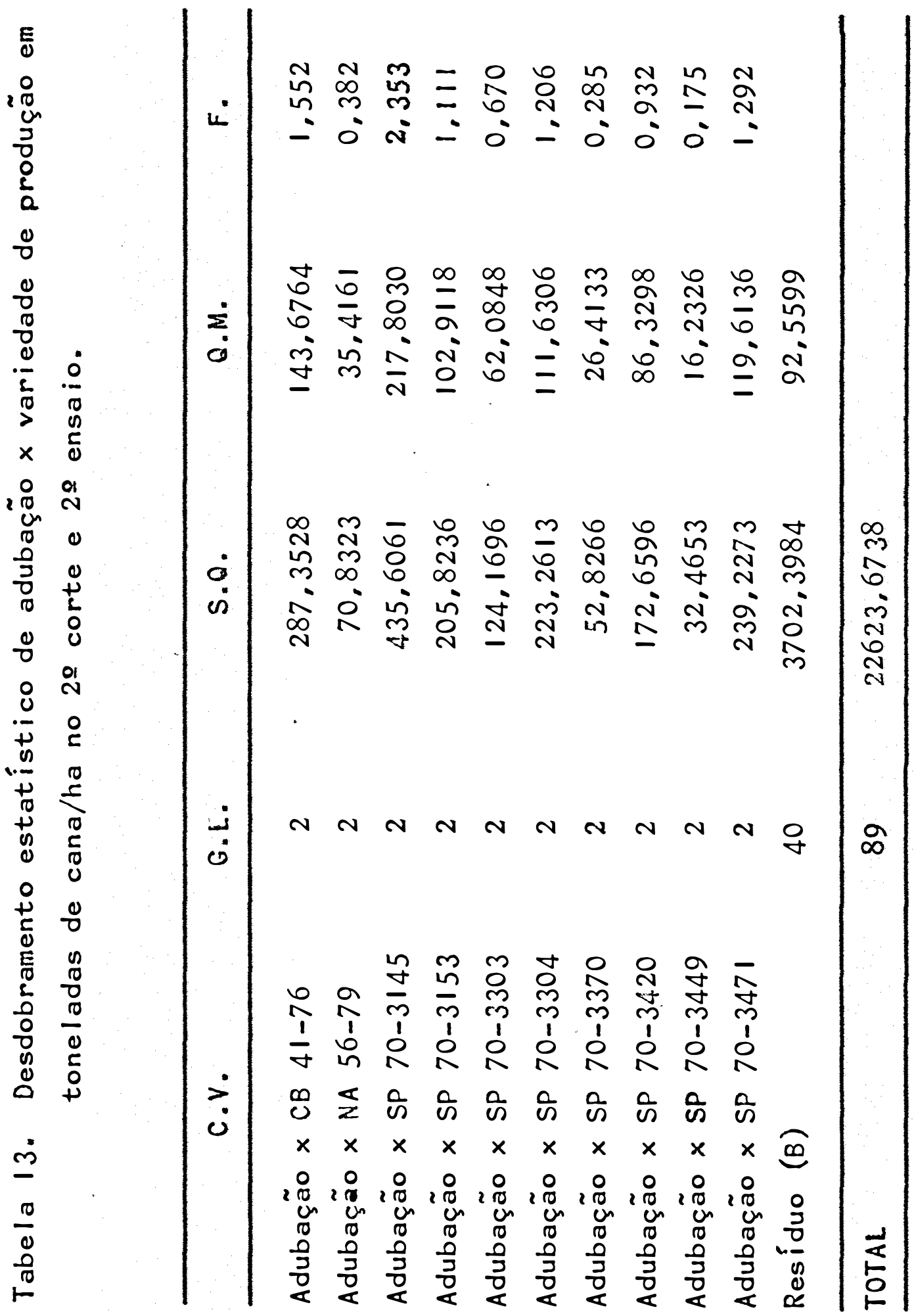




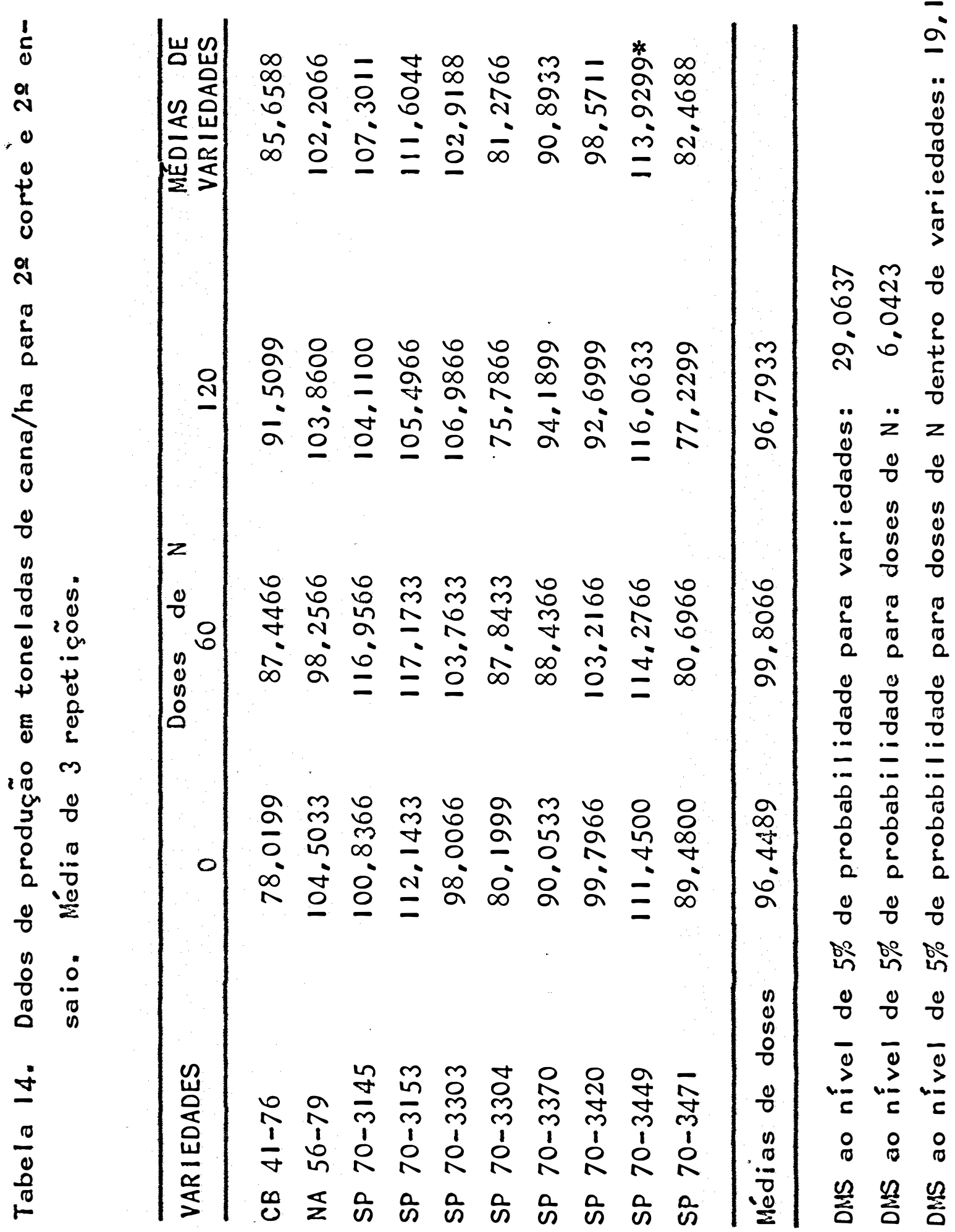




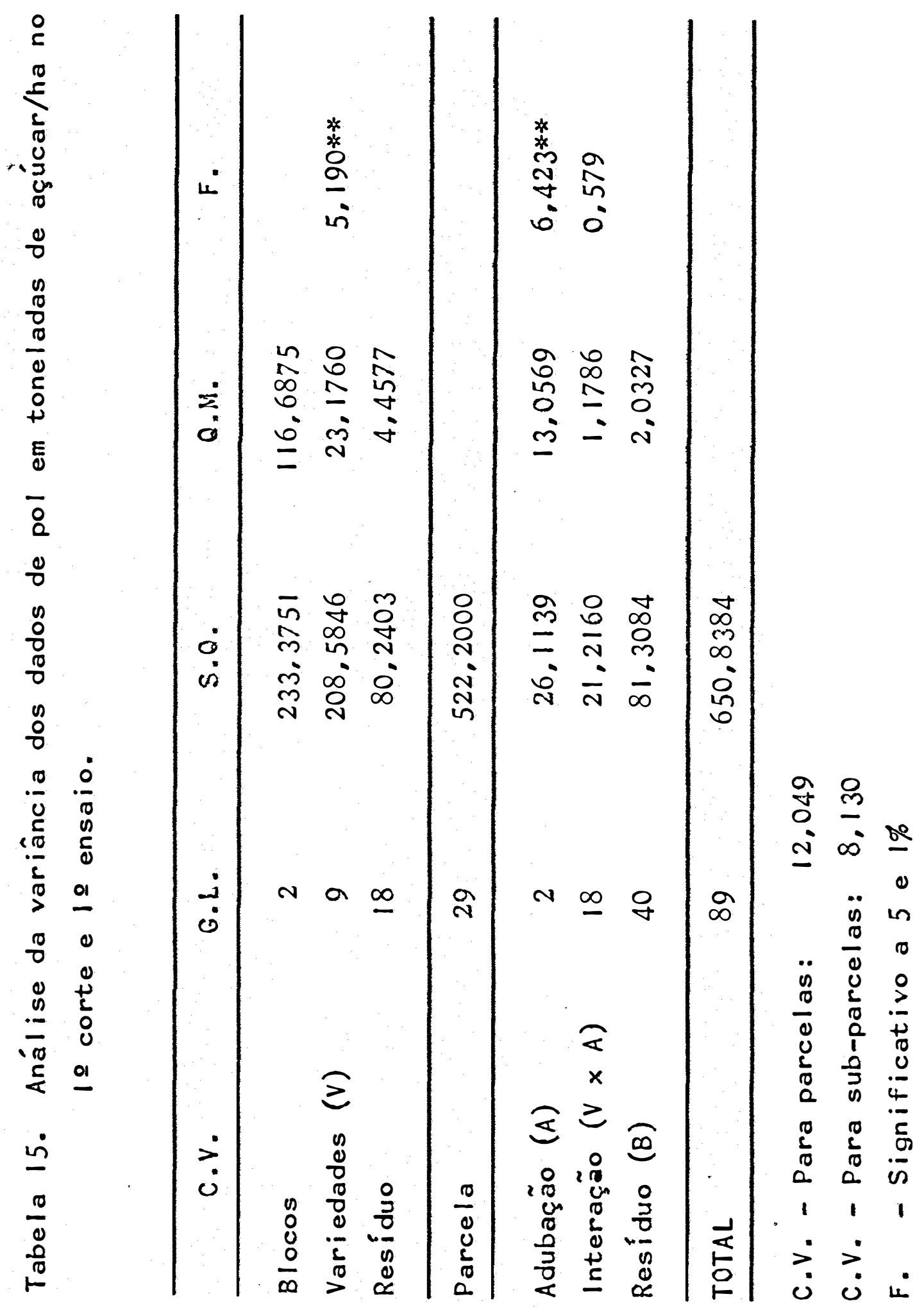


estatístico o qual é apresentado na tabela 16. Esta tabela também mostra as interações não respondendo ao tratamento com as variedades, se comportando de maneira diferente para os 3 níveis de adubação.

A tabela 17 mostra as produções de açúcar ob tidas por variedades. Observa-se que a produção maior perten ce a SP 70-3449, embora não estatisticamente, com a média mais alta entre todas as variedades inclusive a NA 56-79 que, como já foi citado, está servindo como termo comparativo por ser considerada pelos técnicos como uma das melhores.

0 comportamento varietal de SP 70-3449 nova mente volta demonstrar bom desempenho nos 3 niveis de aduba ção utilizados, provando não depender da adubação nitrogenada para apresentar alta produção de açúcar.

Os mesmos tratamentos estatísticos foram apli cados nos dados obtidos para o 20 corte deste ensaio. Assim, a tabela 18 trata da análise de variância onde a significância para os níveis de 5 e $1 \%$ é comprovada mostrando que a aduba ção influiu na produção de açúcar.

O desdobramento (tabela 19) também apresentou significancia para os dados das variedades SP 70-3145 e SP 703370 que responderam melhor e, mais especificamente, com maio res produções de açúcar.

Na tabela 20 os comportamentos varietais estão dispostos e analisados e os resultados mostram respostas para a variedade SP 70-3449 não reagindo a adubação em termos 


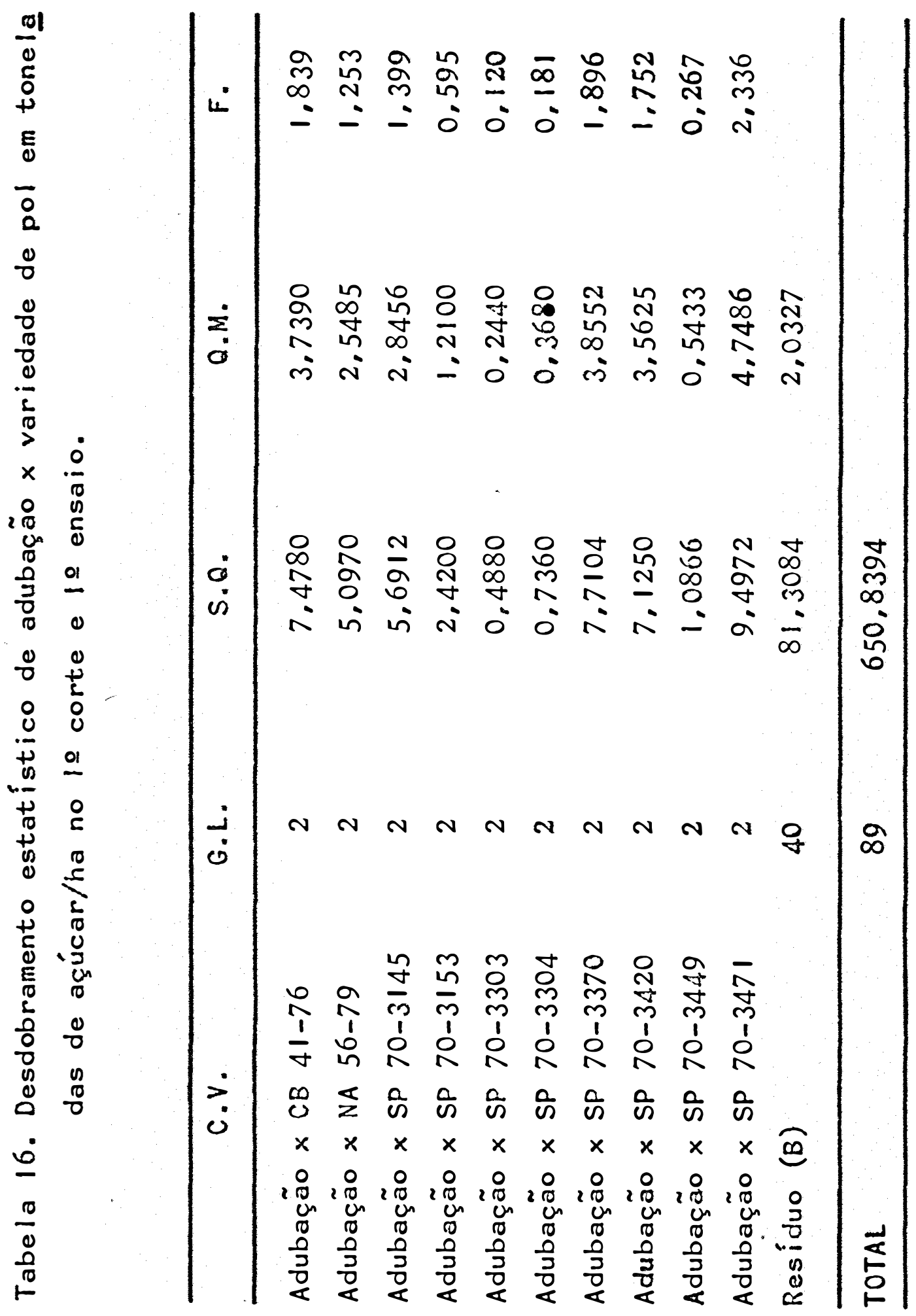




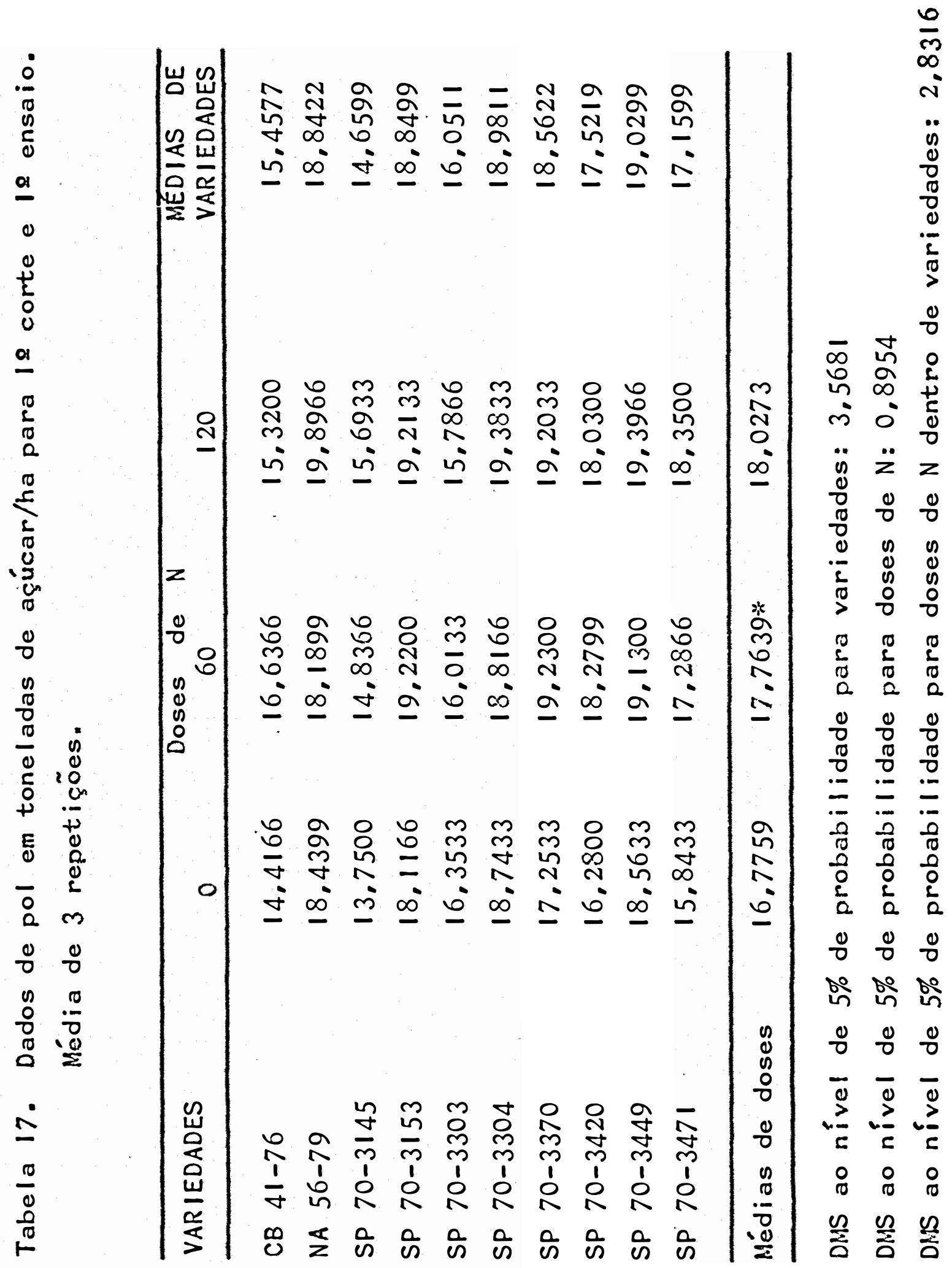




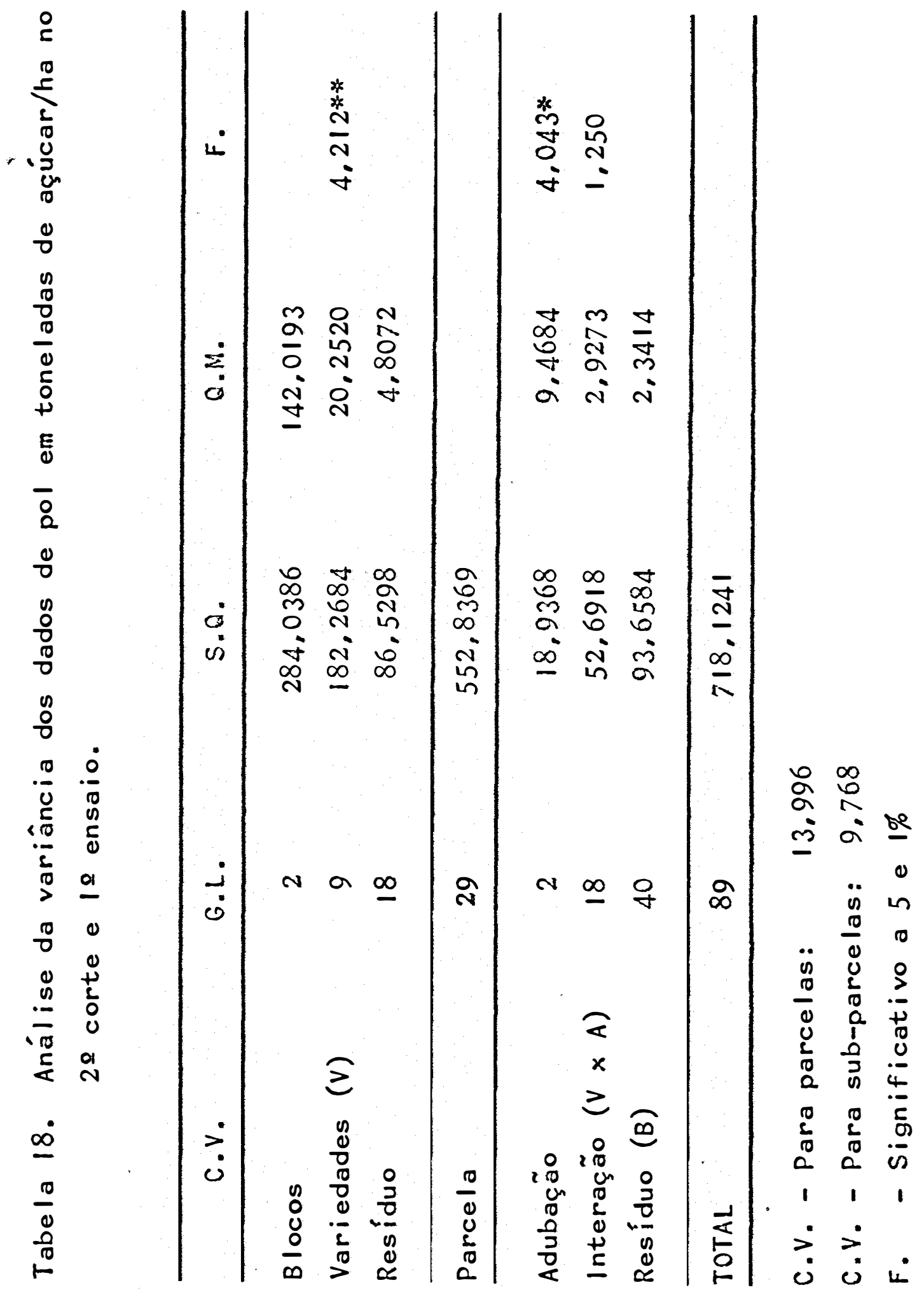




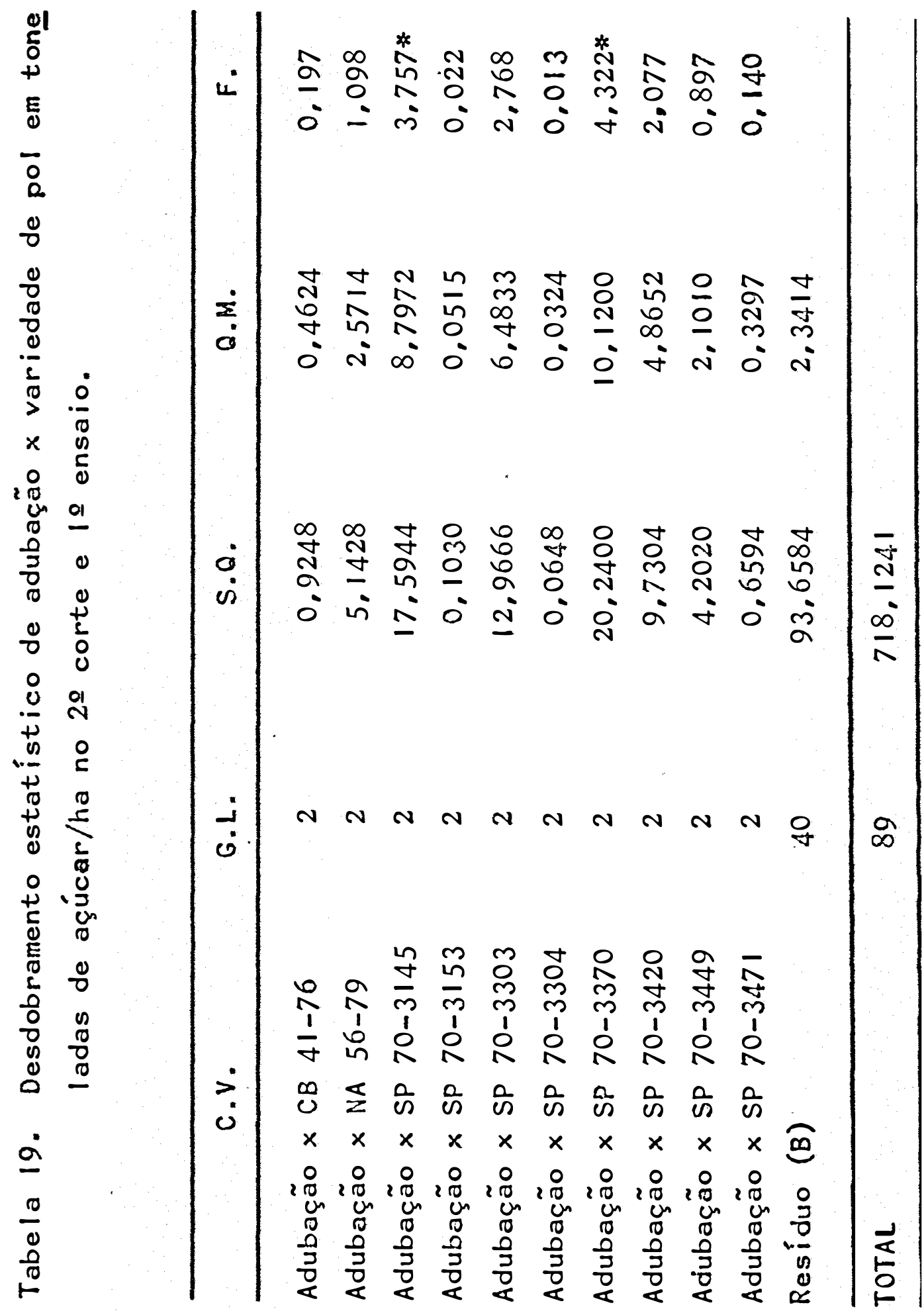




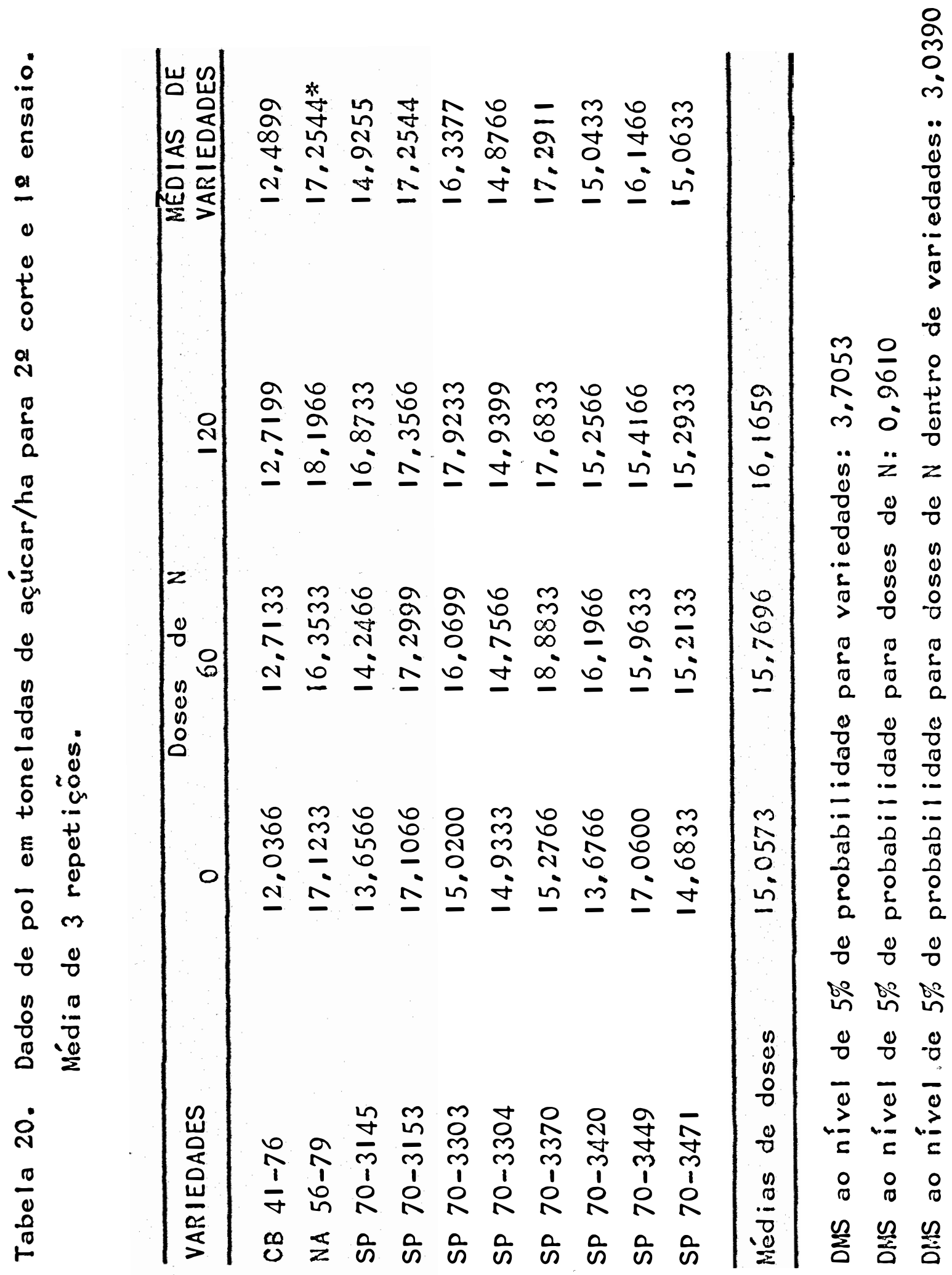


de produção de açúcar, pois sua produção ao nível o (zero) de $\mathrm{N}$ foi maior acusando decréscimo para as de 60 e $120 \mathrm{~kg} \mathrm{~N} / \mathrm{ha}$. Isto indica que a produção de açúcar é mais dependente da tone lagem de cana produzida, do que do teor do mesmo na planta

A SP 70-3370 apresentou a maior média sendo que o mesmo não ocorreu com a SP 70-3/45 com média bem menor que a apresentada pela NA 56-79.

No primeiro corte do 20 ensaio a análise de vạ riância é apresentada na tabela 21. Através dela, observa- se que o conjunto de variedades não reagiu a adubação como um to do, mas, observando-se o resultado deste teste para adubação nota-se significância para este item, demonstrando que algumas delas, em particular deve ter reagido de forma mais incisiva.

Na busca da determinação deste comportamento particular efetuou-se o desdobramento dos dados e a tabela 22 foi construída. Ela demonstra que a interação adubação $\times$ vari edade SP 70-3153 e SP 70-3304 apresentaram significância positiva ao nível de 5 e $1 \%$ para a primeira e a $5 \%$ para a segunda, numa clara demonstração de produções maiores em função da adubação nitrogenada.

Para se determinar o nível que isto ocorreu utilizou-se da tabela 23 onde o comportamento varietal $\dot{e}$ analisado. Observa-se que as variedades citadas apresentavam seu melhor desempento ao nivel de $60 \mathrm{~kg} \mathrm{~N} / \mathrm{ha}$.

A variedade SP 70-3449, mais uma vez, se comportou de maneira idêntica, isto é, produziu quantidades iguais 


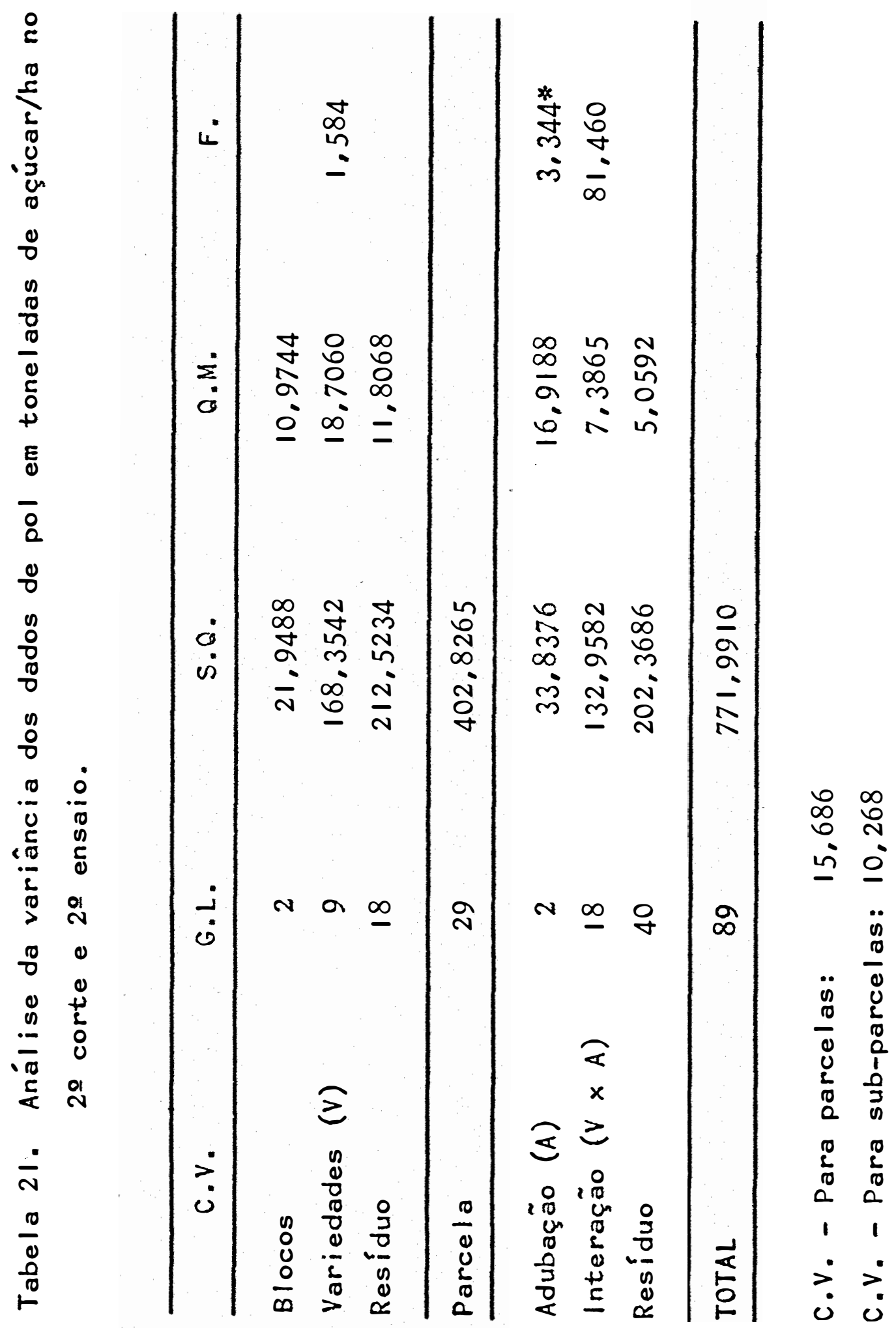




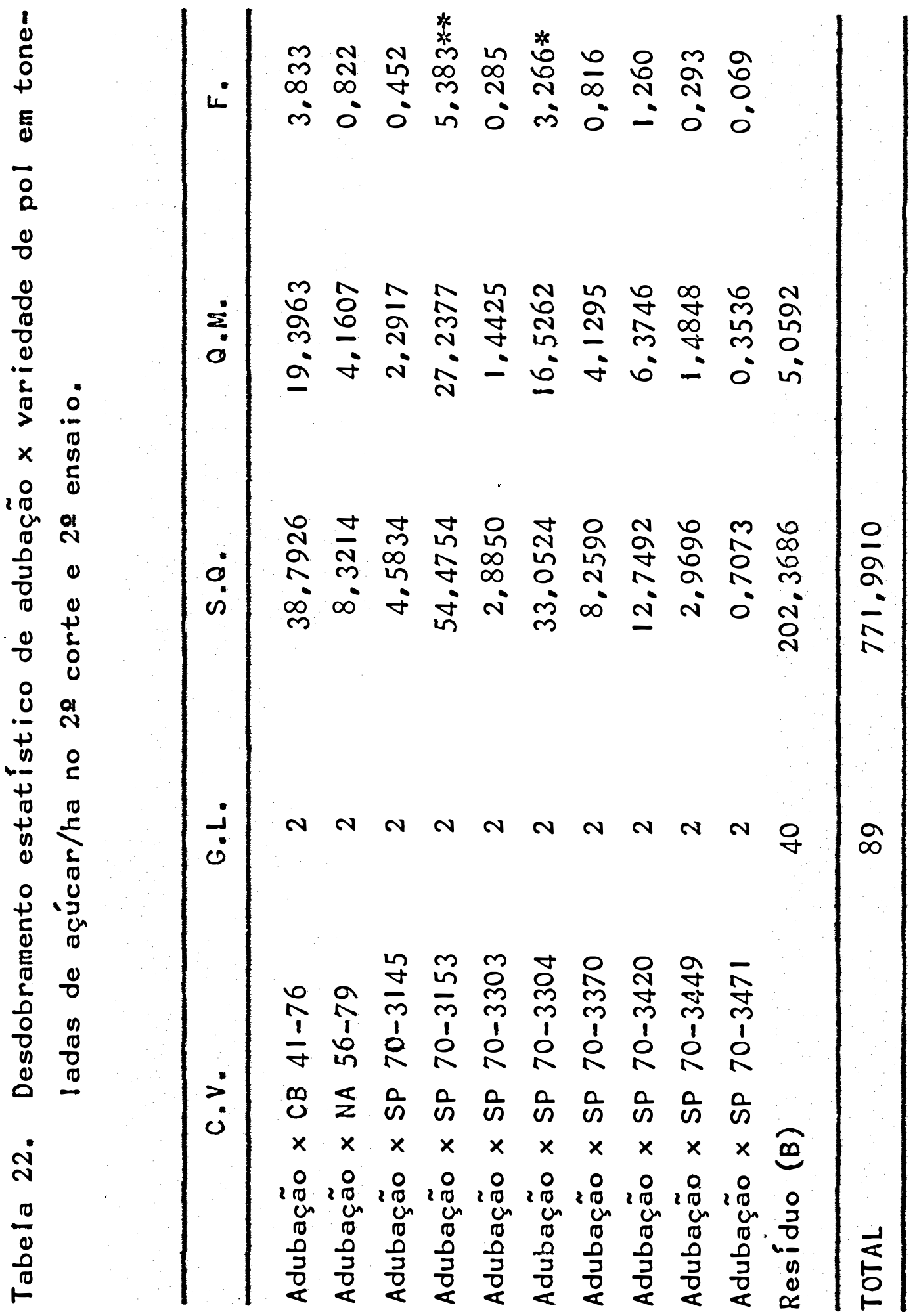




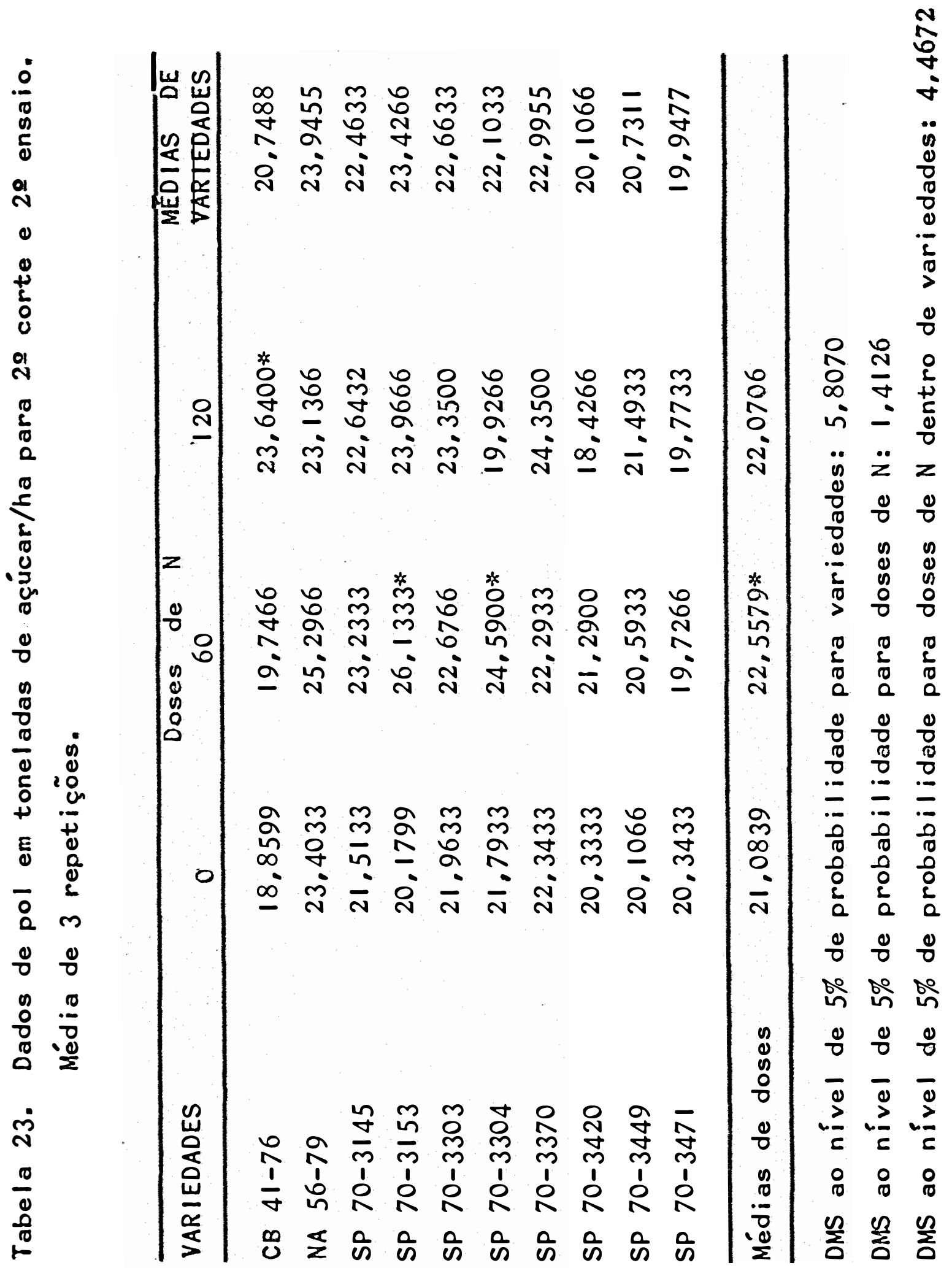


para os 3 níveis de adubação.

Finalmente em relação a este tópico de análise, qual seja a pol, a tabela 24 traz os resultados de variáncia -para o 22 ensaio.

A significância ao nível de $5 \%$ ocorreu em rela ção a variedades e não a adubação, ainda que, diferenças hajam ocorrido.

Com o desdobramento efetuado e apresentado na tabela 25 nota-se que a regra geral permaneceu: não se obteve significância estatística para a interação adubação com variedades.

Já na análise da tabela 26, observa-se que a continuidade do comportamento se confirma. A variedade NA 5679 produziu as maiores quantidades de açúcar independentemente dos níveis e da adubação utilizada. 


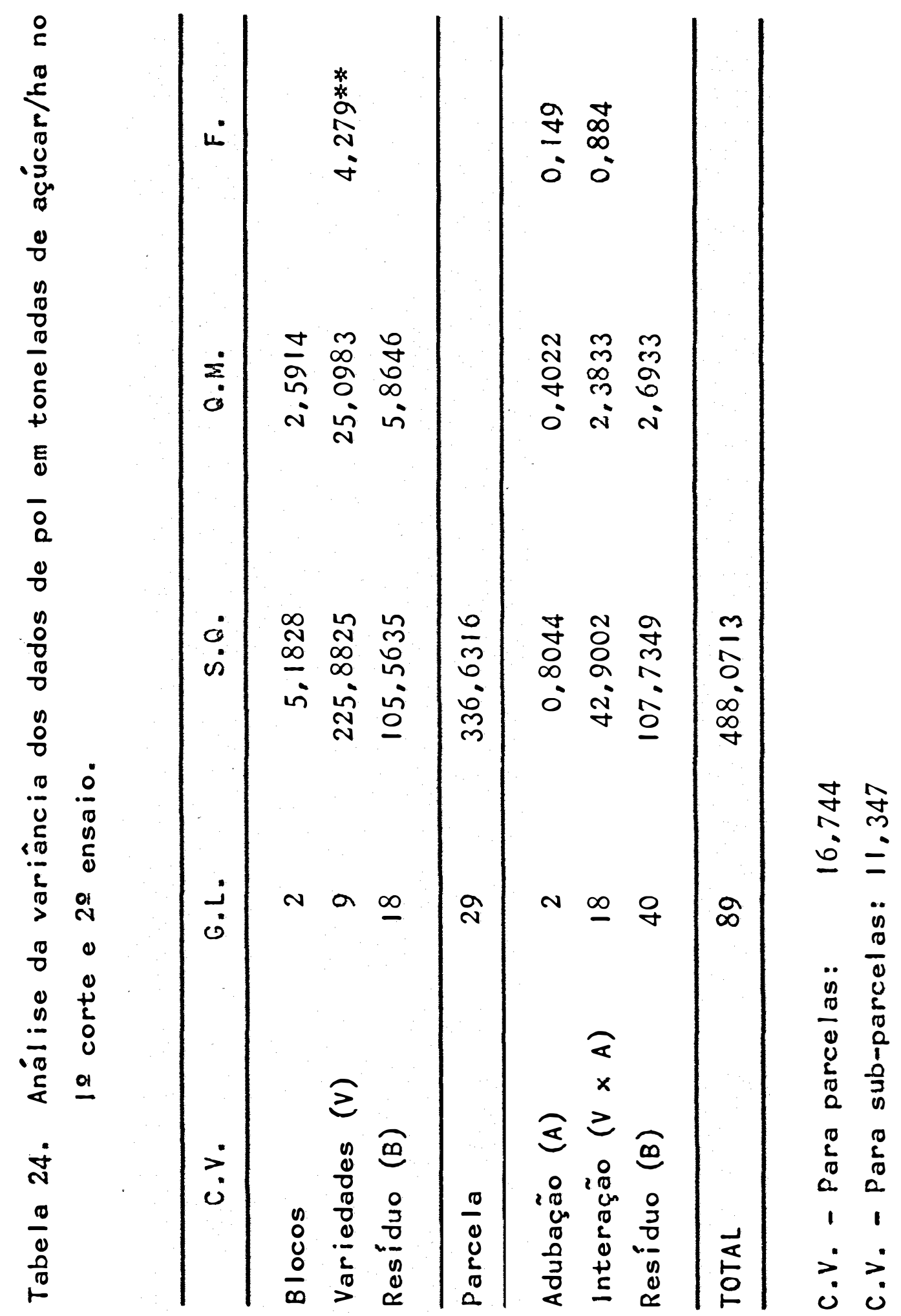




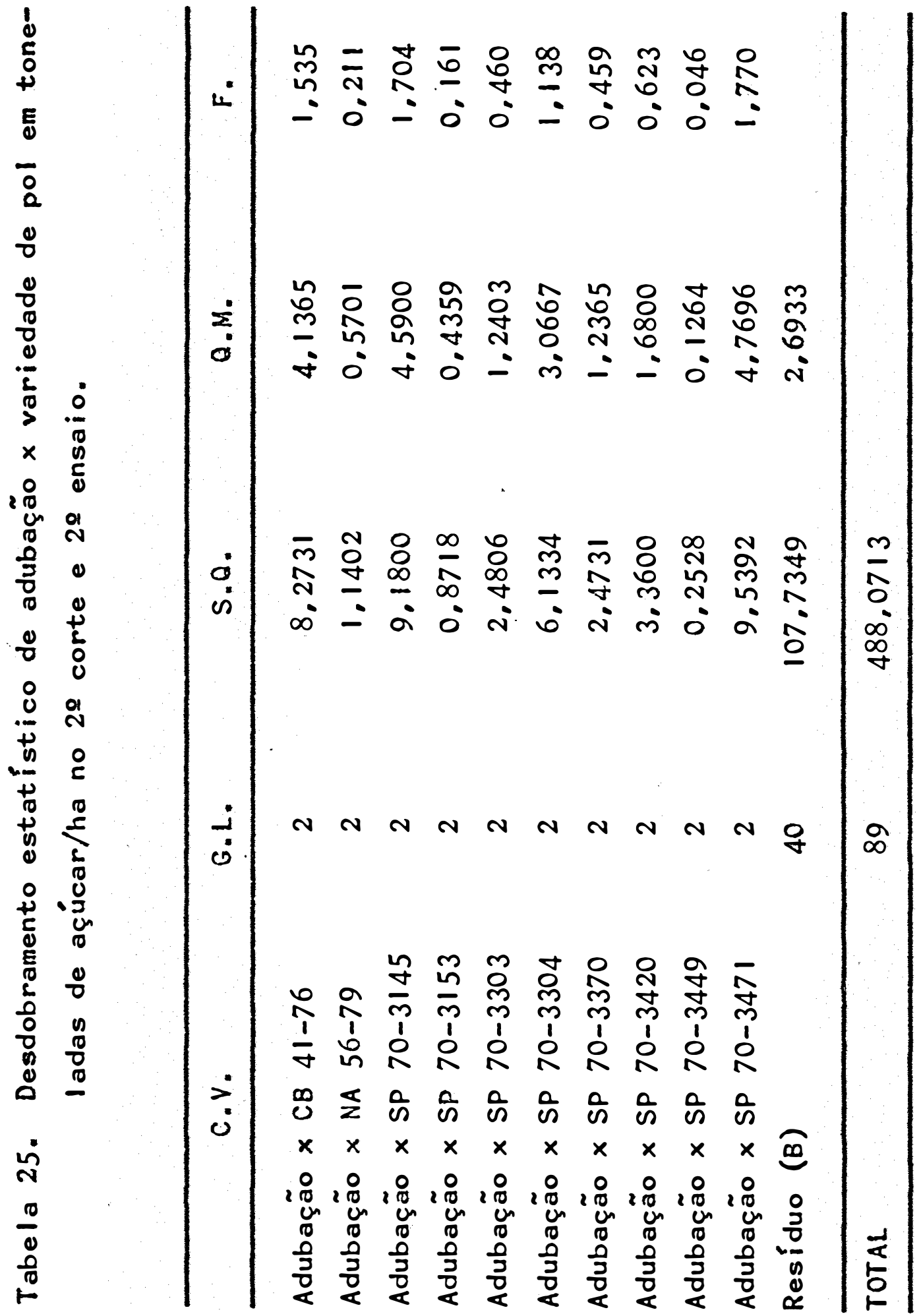


45.

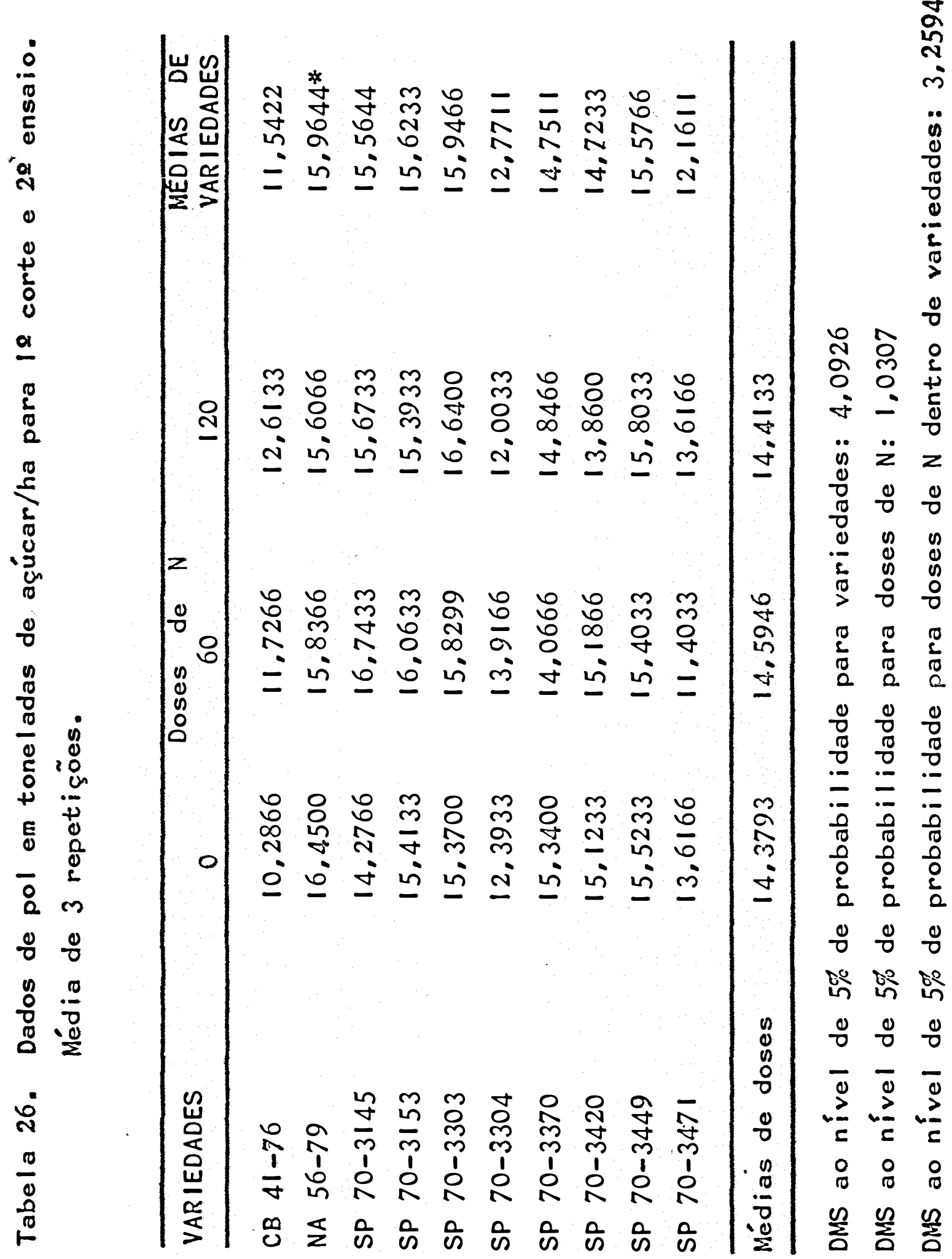


5. CONCLUSÕES

Através da análise dos dados chegou-se as se guintes conclusões:

1. Apenas algumas variedades mostram que não houve respostas a adubação nitrogenada, enquanto que a maio ria não mostrou diferenças significativas na produção devido ao fertilizante.

2. Com relação a Pol houve melhores diferenças na variedade NA 56-79 do que nas demais variedades reforçando o conceito de ser considerada a melhor variedade ainda hoje.

3. Poderia ser admitido que a melhor variedade foi a SP 70-3449 que apresentou uma prodição de cana e de açúcar relativamente elevada. independentemente da adubação nitrogenada. 
6. LITERATURA CITADA

AlVAREZ, R.; AMARAL, A.Z. e ARRUDA, H.V., 1960. Ensaios de adu bação N-P-K em cana de açúcar. Bragantia, Campinas, 63: $1061-1069$.

ALVAREZ, R.; VERDADE. F. C. e OLIVEIRA, H., 1963. Fracionamento da dose de nitrogênio na cultura de cana-de-açúcar. Bragantia, Campinas, 22: LI-LIV.

ARRUDA, H. V., 1960. Adubação nitrogenada na cana-de-açúcar . Bragantia, Campinas, 19:1105-1110.

ASO, J. P. e FOGLIATA, F. A., 1963. El aspecto economico de la fertilization nitrogenada en caña de azucar. Revista Agro nomica Noroeste Argentino, 1:4356.

AZEREDO, D. F.. MOTA, J. S., MANHÃES, M. S. e ROBAina, A. A. , 1980. Adubação nitrogenada em cana-soca. Saccharum. São Paulo, 3:35-38. 
COOPERSUCAR, 1980. Amostragem e análise de cana de açúcar. Apostila Coop. Central Prod. Accúcar Álcool, SP. 37p.

ESPIRONELO, A., 1977. Efeitos da adubação nitrogenada em cana de açúcar. Revista Brasileira de Ciência do Solo, 1:76-81.

LANE, M. e EYNON, L., 1923. Determination of redution sugars by means of fehling's solution with methylene blue as internal indicator. J. Soc. Shem. Industry, 42:32-37.

HALLAIS, P., 1955. Nutrition and Soils. Foliar Diagnosis. AR. Mauritius Sugar. Ind. Research Inst. France. Mauritius: $41-53$.

HUMBERT, R. P., 1955. Field experimentation to correlate soil and plant analysis with fields of cane and sugar. Hawaiian. Platers Record, 55:129-136.

MALAVOLTA, E.; PIMENTEL GOMES, F.; COURY, T.; ABREU, C.P.; VAL SECCHI, 0.; HAAG, H.P.; BRASIL SOBRINHO, M. O. C.; MELLO, F. A. F.; ARZOLLA, J. D. P.; ARZOLla, S.; RANZANI, G. ; KIEHL, E. J.; CROCOMO, O. J.; MENARD, L.N.; NOVAIS, R. F.; FREIRE, O. e OLIVEIRA, E. R., 1963. A diagnose foliar na cana-de-açúcar. IV. Resultados de 40 ensaios fatoriais NPK $3 \times 3 \times 3$, primeiro corte no Estado de São Paulo. Escola Supe rior de Agricultura de Piracicaba, São Paulo - Brasil (s. ed.), $47 p$.

MUSA, M.M., 1968. Nitrogenous fertilizer transformations in the Sudan Gezira Soil. I. Ammonia Volatilization losses fol lowing surface applications of urea and ammonium sulphate. Plant and Soil, 28:413-421. 
ORLANDO FILHO, J.; ZAMBELLO JUNIOR, E. e SOUSA, J.A.G.C., 197\%. Adubação nitrogenada em 4 var. de cana-planta, em solo La tossol Vermelho Escuro orto - Brasil Acucareiro, 89:176-184.

'ORLANDO FILHO, J. e ZAMBELLO JUNIOR, E., 1979. Influência varietal na adubação nitrogenada. Boletim Técnico PLANALSUCAR, Sec. A. Piracicaba, I. 1:25-50.

ORLANDO FILHO, J.; ZAMBELLO JUNIOR, E. e LEME, E.J., 1980. Efeito da irrigação sobre a adubação NPK em cana-planta, var. CB 41-76. Bol. Téc. PLANALSUCAR, Piracicaba, 2, 2: 31-60.

ORTEGA, D. e SEGURA, G., 1963. Época de aplicacion del nitrogeno en caña de azucar. Agronomia Tropical. Maracay, Vene zuela, 13:139-148.

RUSCHEL, A.P.; MATSUI, E.; FILHO, J.O. e BITTENCOURT, V. C. , 1977. Closed system nitrogen balance studies in sugar cane utilizing 15 - ammonium sulphate. In: Congr. Int. Soc. Sug. Cane Tech. Proceedlings, S. Paulo, 2: 1539-1547.

SEGURA, L. G. e MARTINEZ, E.M., 1973. Efecto de fuentes, ni veles y numero de aplicaciones de nitrogeno sobre la caña de açucar (a) - Agronomia Tropical - Maracay - Venezuela. 1:15-28.

STANFORD, G., 1963. Sugarcane quality and nitrogen fertilization. The Hawaiian Planter's Record. Hawai, 4:289-318.

STURION, A.C. e FERNANDES, A.C., 1979. Análise direta da cana de açúcar sobre método da prensa hidráulica. Bol. Técn. COOPERSUCAR, São Paulo, 8:12-15. 
WU, W.Y. e LOH, C.S., 1963. Report on the response te nitrogen fertilizer of the sugarcane variety $F$ 152. Soils and Fertilizers in Taiwan, p.81.

TEIXEIRA, N.T.. 1978. Avaliação da forma de nitrogênio solú vel como método para diagnose foliar em cana-de-açúcar (Saccharum officinarum, L.) variedade NA 56-62. Piracicaba , ESALQ/USP, 7Ip. (Tese de Mestrado).

TOIT da F.L., 1967. The use and efficacy of different forms of nitrogen in sugarcane. The South African Sugar Journal. African, 3:213-224.

TOLEDO, F.F. e NOVAIS, R.F., 1962. Cana de açúcar: adubação nitrogenada e cobertura. Revista da Agricultura, Piracicaba, 37: $107-112$.

YOON, C.N., 1971. Souces of nitrogen on the growth and yield of sugarcane. The Malaysian Agricultural Journal. Malaysia, $1: 69-76$.

YOON, C.N. e KOK, C.A., 1970. Effects of nitrogen on the growth and yield of thru clones of sugarcane. 11. Plant Cane. The Malaysian Agricultural Journal. Malaysia, 46: 270 284. 